\title{
Field Demonstration and Transition of SCAPS Direct Push VOC In-Situ Sensing Technologies
}

\author{
DOE Interagency Agreement No. DE-A105-98OR22663
}

\section{Introduction}

Currently, over 40,000 sites contaminated with subsurface hazardous waste are known that require cleanup (Wise 1997). Approximately $30 \%$ of all underground storage tanks (USTs) have leaked hazardous chemicals (Dowd 1984). Cost projections for environmental restoration of these sites range from $\$ 200$ billion to $\$ 2$ trillion (McDonald et al. 1994). Characterization of the vertical and horizontal extent of subsurface soil and groundwater contamination is required before an appropriate remediation technology can be selected for site cleanup. Site characterization of subsurface contaminants by conventional techniques is costly and time consuming.

The Department of Defense (DoD) has developed rapid, in situ screening techniques for subsurface detection of a variety of hazardous waste contaminants using the Site Characterization and Analysis Penetrometer System (SCAPS). SCAPS sensor probes are often designed with standard geophysical sensors coupled to sensors designed to detect specific contaminant classes. Contaminant sensors developed to date include sensors for petroleum, oil and lubricants (Aptiz et al.; Davis, et al., and Porter 1995; Davis et al. 1997), explosive residue (Cespedes et al 1995; Buttner et al. 1997), heavy metals (Miles, et al. 1997) and volatile organic compounds (VOC) (Davis et al. 1997).

The primary objective of this project was to evaluate the ability of two in-situ VOC samplers in combination with the direct sampling ion trap mass spectrometer (DSITMS) to provide rapid in situ screening for VOC contamination. The technologies were evaluated by performing in situ VOC measurements and collecting verification soil samples that were analyzed by conventional EPA methods. The technologies chosen were the Vadose Sparge (VS) and the Membrane Interface Probe (MIP) sensing systems. This site evaluation in combination with other site evaluations will be used to facilitate the acceptance of the technology by the regulatory and user communities. A secondary objective of the project was to train Department of Energy (DOE) and U.S. Army Corps of Engineers (CE) personnel who operate the SCAPS in the operation of these technologies. The work reported herein was conducted by the U.S. Army Engineer Research and Development Center (CEERD), Environmental Laboratory, under leveraged sponsorship of the U.S. Department of Energy (DOE), Oak Ridge National Laboratory (ORNL), Interagency Agreement Number DE-AI05-98OR22663 and the Environmental Security Technology Certification Program, Tri-Service SCAPS (VOC) Demonstration/Validation Project Number 199603. 


\section{DISCLAIMER}

This report was prepared as an account of work sponsored by an agency of the United States Government. Neither the United States Government nor any agency thereof, nor any of their employees, make any warranty, express or implied, or assumes any legal liability or responsibility for the accuracy, completeness, or usefulness of any information, apparatus, product, or process disclosed, or represents that its use would not infringe privately owned rights. Reference herein to any specific commercial product, process, or service by trade name, trademark, manufacturer, or otherwise does not necessarily constitute or imply its endorsement, recommendation, or favoring by the United States Government or any agency thereof. The views and opinions of authors expressed herein do not necessarily state or reflect those of the United States Government or any agency thereof. 


\section{DISCLAIMER}

Portions of this document may be illegible in electronic image products. Images are produced from the best available original document. 


\section{RECEIVED}

ABSTRACT

Field Demonstration and Transition of SCAPS Direct Push VOC In-Situ Sensing Technologies

DOE Interagency Agreement No. DE-A105-98OR22663

The Utility and cost effectiveness of in situ, direct sparging of volatile organic compounds (VOC) from groundwater has been previously demonstrated using the Hydrosparge sensor deployed using the Site Characterization and Analysis Penetrometer System (SCAPS). This technology was cooperatively developed by the DOE Oak ridge National Laboratory and the U.S. Army Engineer Research and Development Center, Waterways Experiment Station. New VOC sensor technology has recently been developed to improve the efficiency of the Hydrosparge technology.

The primary objective of this project was to demonstrate two in-situ VOC samplers in combination with the direct sampling ion trap mass spectrometer (DSITMS). The technologies chosen were the Vadose Sparge and the Membrane Interface Probe (MIP) sensing systems. A secondary objective of the project was to train CE SCAPS and DOE personnel in the operation of these technologies.

The project objectives were achieved at two demonstration sites that showed the newer VOC technologies capable of providing in situ contaminant measurements at two to four times the rate of the previously demonstrated Hydrosparge sensor. The results of the project provide initial results supporting the utility of these new technologies to provide rapid site characterization of VOC contaminants in the subsurface. 


\section{Materials and Methods}

\section{Site Characterization and Analysis Penetrometer System}

The SCAPS consists of the cone penetrometer truck, enclosed support trailer containing decontamination wash water and grout pumping systems, and a mobile analytical laboratory van. The penetrometer with its associated sensor and sampler systems is advanced into the soil using a hydraulic ram, with the SCAPS truck providing a 20 ton reaction mass. A digging clearance was obtained prior to performing any penetrations in compliance base regulations at both demonstration sites and the SCAPS Safety Plan.

The SCAPS soil classification sensor measures resistance to penetration and sleeve friction. Strain gages mounted in the penetrometer cone tip and sleeve measure these forces and provide soil classification in accordance with procedures described in American Society for Testing and Materials (ASTM) Method D3441 (ASTM 1995). A more detailed description of the SCAPS soil classification sensor is provided in Lee et al. (1993). Normal operating procedures include calibration of the soil classification sensor at the beginning of each investigation and calibration checks periodically during normal operations.

\section{Membrane Interface Probe}

The MIP (Geoprobe Systems, Inc.) is a permeable membrane device used to sample volatile contaminants at discrete depths after it is pushed to depth in soil or other unconsolidated materials. A thin film membrane is impregnated into a stainless steel screen on the face of the probe (Figure 1). This membrane is heated to $100-120^{\circ} \mathrm{C}$ leading to rapid diffusion of VOC contaminants across the membrane into the He carrier gas that flushes the back of the membrane and transports the contaminants to the above ground DSITMS for identification and quantification. A detailed description of the operation of the MIP and the DSITMS is provided in Appendix A.

\section{Vadose Sparge}

The VS consists of a soil purge and sampling system integrated with a standard geophysical cone soil stratigraphy sensor (Figure 2). Air flow through the pneumatic system is controlled by two pumps, one to push air out of the sampler purge port and one to pull the sample vapor through the umbilical to the up-hole DSITMS. Both pumps are regulated to the same flow rate (typically $200 \mathrm{~mL} / \mathrm{min}$ ) using precision needle valves and the flows are continuously monitored and recorded using digital flow meters. The soil vapor sampling system purges a cylindrical soil surface approximately 4 inches long by 1.75 inches in diameter. Air is pumped from the surface through a $1 / 8$ inch ID Teflon tube to four ports located a $0^{\circ}, 90^{\circ}, 180^{\circ}$ and $270^{\circ}$ at the bottom of the vapor sampling module. The air purges the soil surface in an annular space created by a bevel in the probe body. The purge gas is captured by four return sampling ports located at the top of the sampling module. The soil vapor sample purged in this manner is fed through a manifold and umbilical to the surface mounted DSITMS for analysis. 


\section{Site Descriptions}

Based on previous investigations indicating VOC contamination present in complex geologic formations at concentration compatible with the two technologies, two sites were selected for the demonstration: Longhorn Army Ammunition Plant (LHAPP), Karnak, Texas and Lake City Army Ammunition Plant (LCAAP), Blue Springs, Missouri. Each site is discussed in more detail below.

\section{Longhorn Army Ammunition Plant (LHAAP), Karnak, Texas}

The LHAAP is characterized by mixed pine-hardwood forests that cover gently rolling to hilly terrain with an average slope of 3 percent towards the northeast. Most of the terrain at LHAAP slopes 3 percent or less, but slopes as steep as 12 percent may be encountered in the western and northwestern portion of the installation and along the Harrison Bayou flood plain. The LHAAP is surrounded by pine-hardwood forests and agricultural land. The northeastern border is formed by Caddo Lake and Goose Prairie Bayou. Ground surface elevations vary from 170 to $335 \mathrm{ft}$ above sea level. All surface water from LHAAP drains northeastwardly into Caddo Lake via four drainage systems: Saunder's Branch, Harrison Bayou, Central Creek, and Goose Prairie Creek.

The LHAAP is situated on the Wilcox Group, which out-crops over a large part of the eastern half of Harrison County. The Wilcox Group is the bedrock unit beneath more than 99 percent of LHAAP. The Wilcox consists of interbedded sandstones, siltstones, and shales that are variously light gray, red, brown and/or tan. Regionally, the Wilcox has a maximum thickness of $700 \mathrm{ft}$.

Surficial soils across the facility predominately consist of medium plasticity sandy clays with some zones of higher plasticity to a depth of 4 to $10 \mathrm{ft}$ below ground surface (BGS). Beneath this surficial layer, the soils typically consist of low plasticity clays and silty and clayey sands to a depth of at least $59 \mathrm{ft}$ BGS. These deposits are typical of the Wilcox Group. Alluvial deposits, typically including interbedded fine-grained clays, silts, and sands, also occur along drainage features.

Groundwater generally occurs under unconfined conditions, whether in the alluvial or Wilcox Group deposits. Perched and local confining conditions frequently occur within the Wilcox Group deposits due to the high clay content and highly variable stratigraphy. The base of the Wilcox water bearing zone beneath LHAAP is defined by contact of the Wilcox Group with the underlying Midway Group. The Midway Group consists predominately of a very low permeability clay that yields little or no water. The Wilcox is considered as the base of fresh water in the area. The depth to groundwater across the facility ranges from 1 to $70 \mathrm{ft} \mathrm{BGS}$, with depth to groundwater typically being 12 to $16 \mathrm{ft}$. The regional ground water flow direction beneath the facility is generally towards Caddo Lake but varies by site location. At the 
MIP/Vadose Sparge demonstration site, ground water was found in thin seams of sand and gravel above clay zones.

The LHAAP was placed on the national priority list in 1990 with fifty sites selected for restoration: 4 open burning areas; 13 industrial areas; 5 burial pits; 5 sumps/tanks; 4 treatment plants; 16 storage areas; and 3 landfills. The current status of the areas ranges from site investigation to interim remedial action. Contaminants consist of explosives and volatiles in the soil, groundwater and surface water.

The MIP/VS demonstration took place in the sumps project area located in the Plant 3 area rocket motor facility. The sumps project area includes 125 underground sumps and 20 waste rack sumps located throughout the LHAAP production area. Manufacturing areas at the LHAAP were washed down with water to reduce propellant, explosive and pyrotechnics (PEP) dusts which would otherwise collect and pose a safety hazard. Water deactivates ignition sensitive compositions. To dissolve difficult chemical binders, chlorinated solvents were also used in the clean-up of manufacturing areas. These solvents and PEP compositions were washed into sumps with large volumes of water. Based upon previous investigations (Target Environmental Services, Inc. 1994), VOC contaminants in the groundwater include trichloroehtene (TCE) $(0.010$ to $5.0 \mathrm{mg} / \mathrm{L})$, total dichloroehtene (DCE) $(0.020$ to $2.0 \mathrm{mg} / \mathrm{L})$ and, tetrachloroethane (PCE) (around $0.050 \mathrm{mg} / \mathrm{L}$ ).

\section{Lake City Army Ammunition Plant (LCAAP), Blue Springs, Missouri}

The LCAAP lies within the Central Lowlands Physiographic Provence near the boundary between the Osage Plains and the Dissected Till Plains. This section is characterized as a plain of low relief with gently rolling topography comprised of broad, shallow valleys and lowgradient meandering streams. The surface topography in the vicinity of LCAAP consists of rolling uplands traversed by broad steam valleys and flood plains of the Missouri River and Little Blue River. The former flood plain averages about 3 miles in width in this area, with a surface elevation of approximately $735 \mathrm{ft}$ above sea level. Elevations on the upland surface average between 800 and $900 \mathrm{ft}$.

The north and west portions of LCAAP are flat, characteristic of an alluvial plain. The south and east portions of LCAAP are uplands created by headward erosion that exhibit moderate relief with narrow-crested ridges and 150-160 ft of relief from valley floor to ridge top. Area 17, within the Northeast Corner Operable Unit, is typical of a ridged area underlain by uplands sedimentary rocks. Depth to bedrock at the oil and solvent pit area was approximately $40 \mathrm{ft}$.

The LCAAP consists of 33 "areas" that contain approximately 131 suspected or confirmed contaminated sites or solid waste management units (SWMUs). Each of the areas are designated by a numeric qualifier, 1 through 33 . The MIP demonstration took place in the Northeast Corner Operable Unit, Area 17. 
Area 17 consists of four specific areas: the current sanitary landfill; the waste, glass, paint and solvents area; the current pistol range; and the oil and solvent pits area. The oil and solvent pits area consists of three closed disposal pits located immediately adjacent to the current sanitary landfill. Two of the three pits were used for disposal of grease and oil, waste solvent and waste oils. The easternmost pit was used for disposal of demolition waste and domestic refuse. The western and central pits were opened in the 1960s and closed in 1979. Altogether they occupied an estimated $25,000 \mathrm{ft}^{2}$ and reportedly received approximately $10,000 \mathrm{ft}^{3}$ of waste. The easternmost pit was opened in 1977 and closed in 1979. Fill thicknesses of up to $10 \mathrm{ft}$ were indicated by soil boring drilled during the 1990 remedial investigation work. Closure of the three pits did not involve the use of an engineered cover system. Currently, the pits are heavily vegetated with a soil cover typically less than $1 \mathrm{ft}$ thick. Stressed vegetation and small barren areas at the ground surface have been noted at this site. The MIP demonstration took place at the oil and solvent pits area along the gravel road running adjacent to the central pit.

\section{Results and Discussion}

Table 1 summarizes the field activities at the two demonstration sites. Previous sensors demonstrated with the SCAPS have been able to make a maximum of ten to twelve in situ VOC measurements per day (Davis et al, 1998). The MIP and VS demonstrations reported herein achieved rates of 35.4 and 54 measurements per day at LHAAP and LCAAP respectively. This increased productivity allows much higher resolution contaminant mapping, both vertically and horizontally than has been previously possible.

Table 1. Summary of demonstration site activities

\begin{tabular}{|l|l|l|l|l|}
\hline Site & Duration & Penetrations & $\begin{array}{l}\text { Max Depth } \\
\text { (ft BGS })\end{array}$ & Number of VOC Measurements \\
\hline & & & & \\
\hline LHAAP & 8 days & $20(11$ MIP; 9 VS) & 19 & 283 (227 MIP; 55 VS) \\
\hline LCAAP & 3.5 days & 11 & 54 & 188 \\
\hline
\end{tabular}

\section{Longhorn Army Ammunition Plant Demonstration Results}

Both the MIP and the VS where evaluated at the LHAAP demonstration site. As implied by the name, the VS is capable of sampling VOC analytes only in the vadose zone while the MIP can sample VOC analytes in both the vadose and saturated zones. As summarized in Table 1, a larger number of penetrations and measurements were made using the MIP than with the VS. This was done because of the relatively shallow groundwater restricting the utility of the VS at this site. 
rapidly. The rapid screening capabilities of this technology is illustrated in Figure 3 by the collection of four depth discrete VOC samples in only twelve minutes time. This includes the time required to advance the probe to each successive sampling depth. Additional depth discrete data collected at this site is provided in Appendix B.

Validation data were collected to evaluate the function of the MIP relative to conventional technology. The in situ MIP performance was verified by soil sampling and offsite analysis by U.S. EPA Method 8260 . Five of the 11 MIP penetrations were selected for validation sampling. At each penetration location ten discrete soil samples were collected using a direct push soil sampler and subsampling by U.S. EPA Method 5035. Briefly, EPA Method 5035 involves subsampling 4-5 $\mathrm{mL}$ soil from the core and placing the subsample into a preweighed $20 \mathrm{~mL}$ vial containing $5 \mathrm{~mL}$ methanol. The vial is then reweighed to obtain the soil sample weight and the sample is place on ice until it is analyzed by EPA Method 8260 . A detailed description of the soil verification procedure can be found in Appendix A.

Results of the fifty verification soil sampling analyses for the LHAAP demonstration (Figure 4) indicate a strong correlation between the in situ MIP/DSITMS measurements and the ex situ verification sampling and analysis. The bias indicated by the slope value less than 1 could be due to a number of factors including loss of analyte during verification soil sampling or some bias introduced during the procedure used to calibrate the MIP/DSITMS.

\section{Lake City Army Ammunition Plant Demonstration (LCAAP) Results}

The MIP/DSITMS demonstration at the LCAAP was shorter than the LHAAP demonstration but the data production rate was much higher at LCAAP (Table 1). The daily MIP/DSITMS measurement rate was over 50\% higher at LCAAP than at LHAAP. This was due to a number of factors including improved data acquisition and reduction procedures employed at LCAAP and increased familiarity with the MIP technology. Also, less time was devoted to validation sampling at LCAAP (three penetration locations, 11 total validation samples). The data produced during the MIP/DSITMS demonstration was used by the LCAAP site manager in

the base Installation Restoration Program to locate soil boring locations. The full MIP/DSITMS data set collect during the LCAAP demonstration is provided in Appendix C.

The limited verification effort at the LCAAP confirmed the utility of the MIP/DSITMS technology for rapid field screening of VOC contamination. The verification data again indicates a bias between the ex situ soil analysis and the in situ MIP/DSITMS results (Table 2). However, the verification data confirm the capability of the MIP/DSITMS technology to assist in locating a minimum number of conventional sampling points. 
Table 2. Summary of Lake City Army Ammunition Plant MIP in situ results measured in the unsaturated zone compared with ex situ validation samples analyzed using U.S. EPA Method 8260. Lower limits of detection were 2.5 and $1 \mathrm{mg} / \mathrm{kg}$ for EPA 8260 and the MIP, respectively.

\begin{tabular}{|c|c|c|c|c|c|c|c|}
\hline $\begin{array}{c}\text { Sample } \\
\text { Name }\end{array}$ & Depth & $\begin{array}{c}\text { EPA } \\
8260\end{array}$ & MIP & $\begin{array}{c}\text { EPA } \\
8260\end{array}$ & MIP & $\begin{array}{c}\text { EPA } \\
8260\end{array}$ & MIP \\
\hline & (ft BGS) & $\mathrm{mg} / \mathrm{kg}$ & $\mathrm{mg} / \mathrm{kg}$ & $\mathrm{mg} / \mathrm{kg}$ & $\mathrm{mg} / \mathrm{kg}$ & $\mathrm{mg} / \mathrm{kg}$ & $\mathrm{mg} / \mathrm{kg}$ \\
\hline & & $\mathrm{VinCl}$ & $\mathrm{VinCl}$ & $\mathrm{DCE}$ & $\mathrm{DCE}$ & $\mathrm{TCE}$ & $\mathrm{TCE}$ \\
\hline LC17MIP119 & 39 & $\mathrm{BDL}$ & $\mathrm{BDL}$ & $\mathrm{BDL}$ & $\mathrm{BDL}$ & $\mathrm{BDL}$ & 1 \\
\hline LC17MIP119 & 42 & $\mathrm{BDL}$ & $\mathrm{BDL}$ & $\mathrm{BDL}$ & 1 & $\mathrm{BDL}$ & 1.5 \\
\hline LC17MIP119 & 45.5 & $\mathrm{BDL}$ & $\mathrm{BDL}$ & $\mathrm{BDL}$ & 1 & 105 & 2 \\
\hline LC17MIP114 & 8 & $\mathrm{BDL}$ & $\mathrm{BDL}$ & $\mathrm{BDL}$ & $\mathrm{BDL}$ & $\mathrm{BDL}$ & $\mathrm{BDL}$ \\
\hline LC17MIP114 & 16 & $\mathrm{BDL}$ & $\mathrm{BDL}$ & $\mathrm{BDL}$ & $\mathrm{BDL}$ & 58 & $.75 \mathrm{~J}$ \\
\hline LC17MIP114 & 16.8 & $\mathrm{BDL}$ & $\mathrm{BDL}$ & $\mathrm{BDL}$ & $\mathrm{BDL}$ & 63 & $\mathrm{BDL}$ \\
\hline LC17MIP114 & 18 & $\mathrm{BDL}$ & $\mathrm{BDL}$ & $\mathrm{BDL}$ & $0.5 \mathrm{~J}^{*}$ & $\mathrm{BDL}$ & 1.1 \\
\hline LC17MIP112 & 12 & $\mathrm{BDL}$ & 840 & 19609 & 650 & BDL & 98 \\
\hline LC17MIP112 & 16 & 5167 & 320 & 6892 & 240 & BDL & 5 \\
\hline LC17MIP112 & 20 & 786 & 50 & 1658 & 40 & BDL & 1.6 \\
\hline
\end{tabular}

*Estimate reported below detection limit presence of TCE confirmed by mass spectra.

\section{Conclusions}

The data collected during the two demonstrations reported herein fully support the utility of the combined MIP/DSITMS as a powerful tool for rapid assessment of subsurface VOC contamination in both the unsaturated (LCAAP) and saturated (LHAAP) zones.

Validation samples were collected at both LHAAP (50 samples) and LCAAP (11 samples). Agreement between in situ VOC measurements and validation sample results was observed for both demonstrations. Table 2. Summarizes the validation results for the LCAAP. Note that, although the absolute values measured using U.S. EPA Method 8260 are different from those measured in situ with the MIP, the trends are the same for each technique. The larger 
data set collected at LHAAP indicate a strong correlation between the in situ MIP measurements and the ex situ analysis by U.S. EPA Method 8260 . Additional demonstrations are planned with Department of Defense funding to further evaluate this promising technology.

The previously developed direct push Hydrosparge VOC sensing technology currently used by U.S. Army Corps of Engineers District SCAPS site characterization teams has been demonstrated to significantly reduce the cost of site characterization work at Department of Defense investigation sites when compared to conventional monitoring well installation and offsite analysis methods (Davis 1999). The direct push Hydrosparge VOC sensing technology produces a minimal quantity of derived waste and is capable of collecting 10-12 VOC measurements per day at discrete depths and providing near real-time on-site analysis and results. Documented cost saving are typically greater than $50 \%$ when compared to conventional analysis methods.

The MIP/DSITMS VOC sensor probe is equipped to collect soil stratigraphy data during penetration activities and to collect VOC measurements at multiple discrete depths during each penetration. Due to the training aspects associated with the site investigations documented in this report, the MIP/DSITMS VOC sensor technology operational production rates reported in Table 1 should be viewed as conservative estimates. However, the MIP/DSITMS VOC sensing technology provides the added capabilities of collecting soil classification and multiple discrete VOC interrogations per penetration. These added capabilities increase the efficiency and are expected to yield greater cost savings for the MIP/DSITMS compared to the Hydrosparge VOC sensor and to conventional sampling technologies. 


\section{GeoProbe Systems}

Membrane Interface Probe

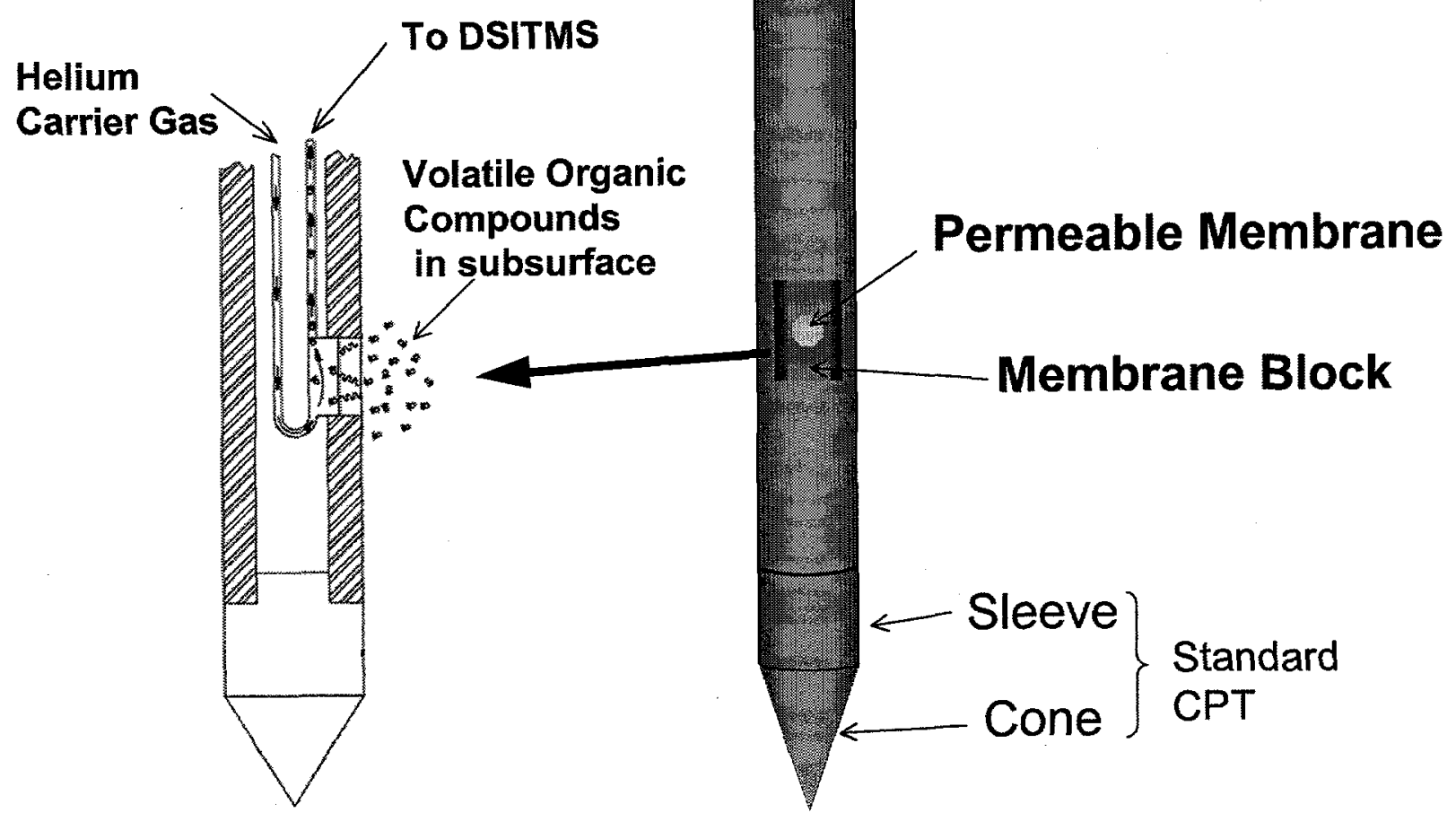

Figure 1. Schematic diagram for membrane interface probe integrated with geophysical cone sensor. 
SCAPS VADOSE SPARGE VOC SAMPLER

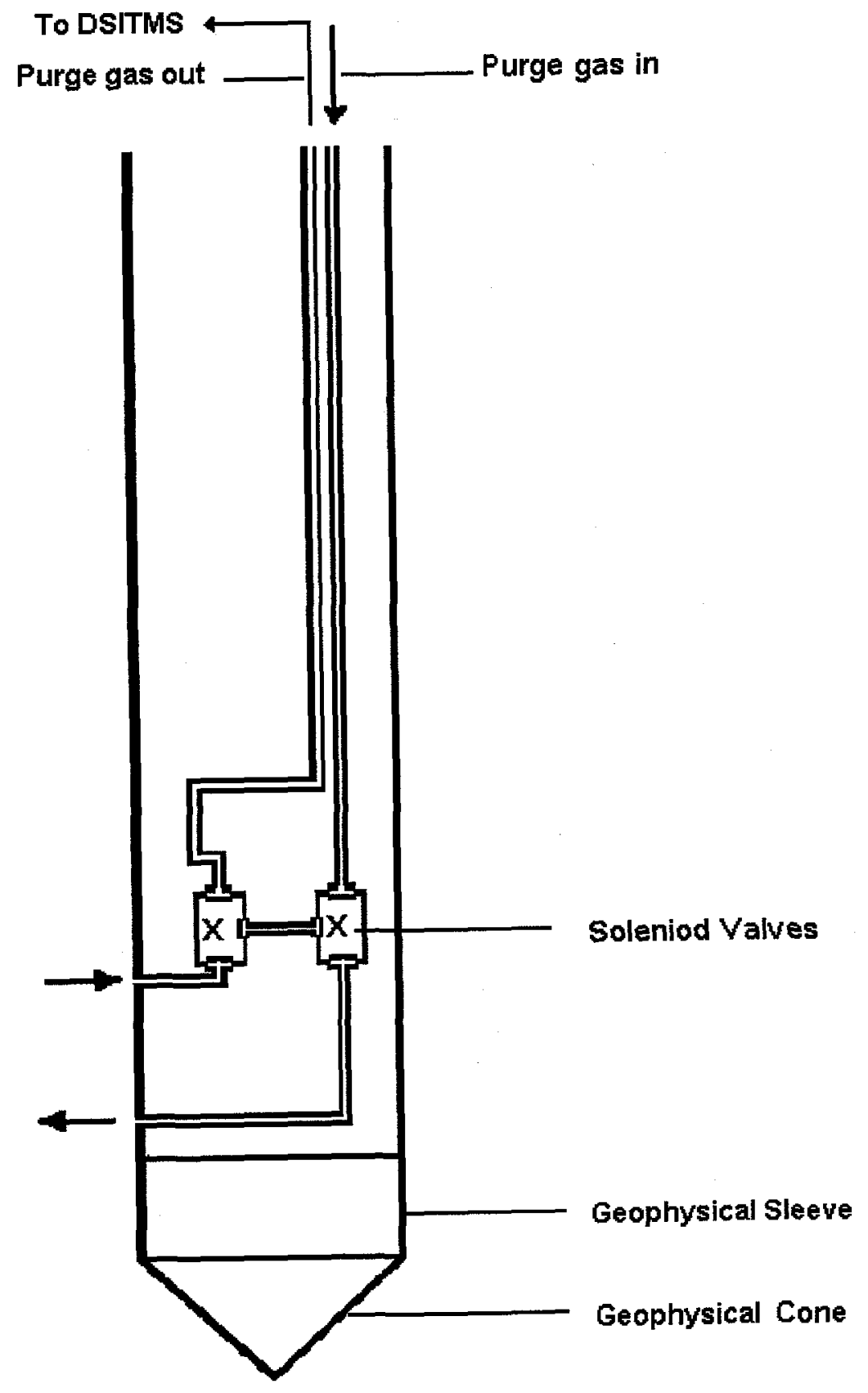

Figure 2. Schematic diagram of vadose sparge VOC sensor. 
Raw Data, LHOLEOG

Longhorn Army Armmunition Plant, Sept 1998

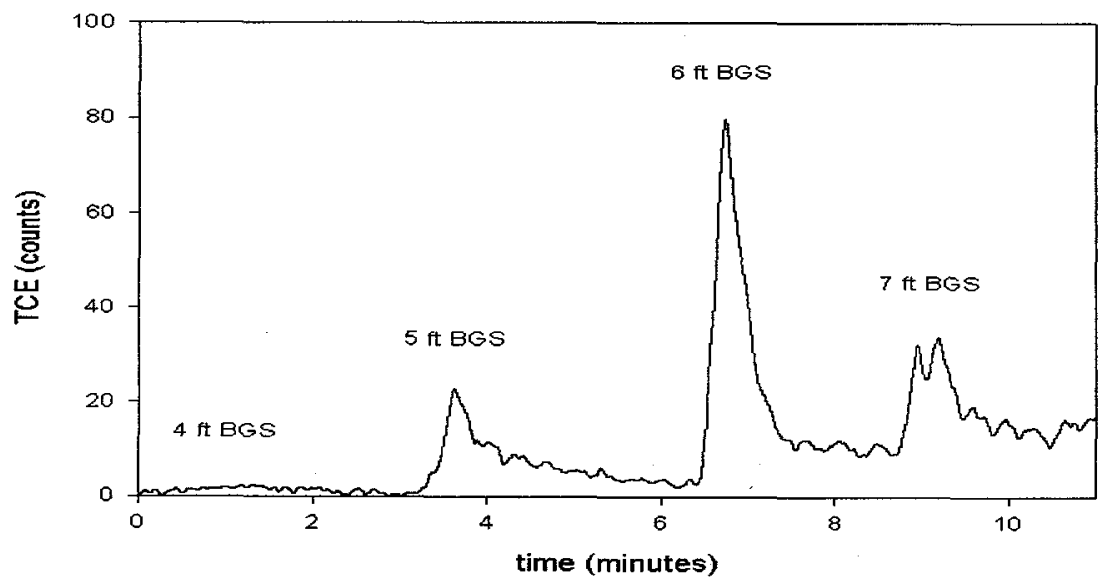

Figure 3. Typical MIP/DSITMS response for in situ measurement of TCE at Longhorn Army Ammunition Plant. 
Comparison of Analyses for VOCs in Soil

Longhom Army Ammunition Plant, Sept 1998

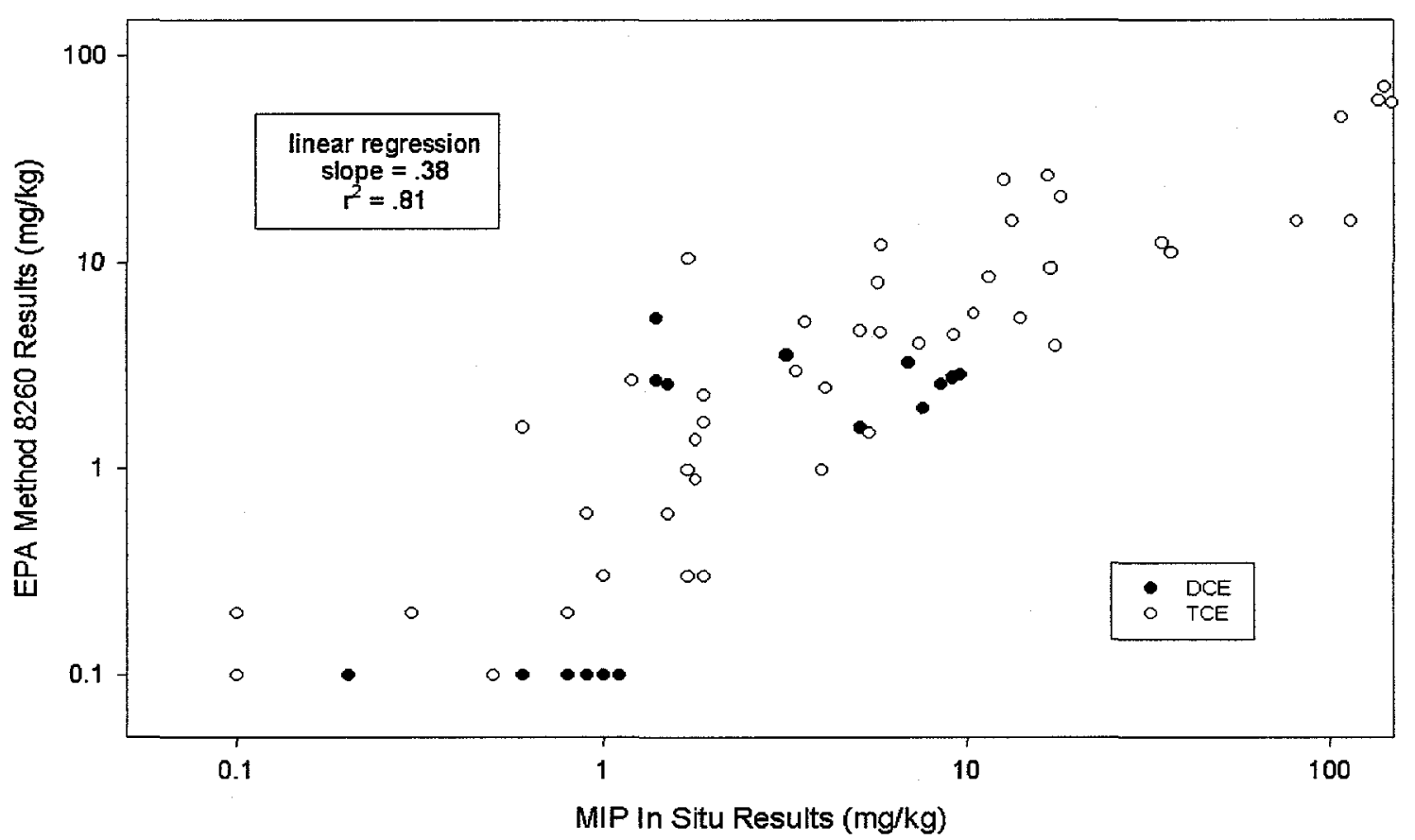

Figure 4. Validation results for MIP in situ measurements compared with ex situ soil sample analyses by U.S. EPA Method 8260 . 


\section{References}

1. M.B. Wise and M.R. Guerin, "Direct Sampling MS for Environmental Screening" Analytical Chemistry 69, 26A-32A, 1997.

2. R.M. Dowd, "Leaking underground storage tanks" Environ. Sci. Technol., 18, 10-14, 1984

3. W.C. McDonald, M.D. Erickson, B.M. Abraham and A. Robbat, Jr., "Developments and Applications of Field Mass Spectrometer", Environmental Sci. Technol., 28, 336A-343A, 1994.

4. S.E. Aptiz, L.M. Borbridge, G.A. Theriault and S.H. Lieberman, "Remote In-Situ Determination of Fuel Products in Soils”Analus, 20, 461-474, 1992.

5. W.M. Davis, P. Jones, B. Porter, "Field Portable Petroleum Analysis for Validation of the Site Characterization and Analysis Penetrometer System Petroleum, Oil and Lubricant Sensor," in Proceedings of the 1995 U.S. EPA/A\&WMA International Symposium on Field Screening Methods for Hazardous and Toxic Chemicals, VIP-47; Air \& Waste Management Association: Pittsburgh, 1995; pp 502-510.

6. W.M. Davis, E.R. Cespedes, L.T. Lee, J.F. Powell and R.A. Goodson, "Rapid delineation of subsurface petroleum contamination using the Site Characterization ans Analysis Penetrometer System" Env. Geology, 29 , 2228-237, 1997.

7. E.R. Cespedes, E.R. Cooper, W.M. Davis, W.J. Buttner, W.C. Vickers, "In-Situ Detection of TNT Contamination using Electrochemical Sensors in Cone Penetrometer Systems" in Proceedings of the Optical Sensing for Environmental and Process Monitoring Symposium, the International Society for Optical Engineering, Washington, D.C., 1995; Vol. 2367, pp 33-42.

8. W.J. Buttner, M. Findlay, W. Vickers, W.M. Davis, E.R. Cespedes, S. Cooper and J.W. Adams, "In situ detection of trinitrotoluene and other nitrated explosives in soils" Anal. Chimica Acta, 17815, 1-9, 1997.

9. B.H. Miles, J. Cortes, E.R. Cespedes, "Laser Induced Breakdown Spectroscopy (LIBS)

Detection of Heavy Metals Using a Cone Penetrometer: System Design and Field Investigation Results" in "Proceedings of the 1997 U.S. EPA/A\&WMA International Symposium on Field Screening Methods for Hazardous and Toxic Chemicals," VIP-71; Air \& Waste Management Association: Pittsburgh, PA, 1997; pp 671-680. 
10. W.M. Davis, J.F. Powell, K. Konecny, J. Furey, C.V. Thompson, M.B. Wise and G. Robitaille, "Rapid In-situ Determination of Volatile Organic Contaminants in Groundwater using the Site Characterization and Analysis Penetrometer System" in "Proceedings of the 1997 U.S. EPA/A\&WMA International Symposium on Field Screening Methods for Hazardous and Toxic Chemicals," VIP-71; Air \& Waste Management Association: Pittsburgh, PA, 1997; pp 464-469.

11. American Society for Testing and Materials (ASTM). "Annual book of ASTM standards" 04.08 (D3441) Philadelphia, PA. 1995.

12. Lee, L.T., Chrestman, A.M., Douglas, D.H., Powell, J. F., and Malone, P.G. "Site investigation with the site characterization and analysis penetrometer system at Fort Dix, New Jersey", Technical Report GL-93-17, U.S. Army Engineer Waterways Experiment Station, Vicksburg, MS.

13. Target Environmental Services, Inc., 1994. "Soil Gas Survey; Longhorn Army Ammunition Plant; LHAAP-12 and LHAAP-16 (Active and Old Landfills) Karnack, TX", prepared for U.S. Army Corps of Engineers, Tulsa District U.S. Army Corps of Engineers, Tulsa District, 1996. "Group IV Pre-Phase III Groundwater Investigation Report - Longhorn Army Ammunition Plant".

14. Davis, W.M., "Tri-Service Site Characterization and Analysis System (SCAPS) validation of the Hydrosparge Volatile Organic Compound Sensor" Technical Report EL-99-XX, U.S. Army Engineer Research and Development Center, Vicksburg, MS. 


\section{Appendix A}

Field Screening of Volatile Organic Compounds in Soil and Groundwater Using the Geoprobe Membrane Interface Probe/Direct Sampling Ion Trap Mass Spectrometer 


\section{Field Screening of Volatile Organic Compounds in Soil and Groundwater Using the Geoprobe Membrane Interface Probe/Direct Sampling Ion Trap Mass Spectrometer}

\section{Application}

The Membrane Interface Probe/Direct Sampling Ion Trap Mass Spectrometer (MIP/DSITMS) system is capable of rapid groundwater and vadose zone characterization using direct push techniques. The MIP/DSITMS is applicable to all locations where direct push techniques can be used. The MIP/DSITMS is comprised of the MIP, a metal/teflon composite membrane that samples volatile organic compounds (VOC) in situ and the DSITMS that identifies and quantifies the VOC analytes. The MIP/DSITMS is capable of multiple, discreet VOC measurements in a single penetration, sampling depths/resolution are determined on a site specific basis.

The MIP was developed by Geoprobe Systems, Inc. (www.georprobesystems.com). The MIP/DSITMS has been used by the U.S. Army Engineer Research and Development Center, Environmental Laboratory, with a standard geophysical cone penetrometer test (CPT) truck capable of advancing direct push sampling tools and has been deployed using other vehicles capable of advancing direct push tools (Geoprobe, Earth Probe, etc.).

The MIP is a permeable membrane device used to detect volatile contaminants as it is driven to depth in soil or other unconsolidated materials. A thin film membrane is impregnated into a stainless steel screen on the face of the probe. This membrane is heated to $100-120^{\circ} \mathrm{C}$ leading to rapid diffusion of VOC contaminants across the membrane into the He carrier gas flushing the back of the membrane and transporting the contaminants to the above ground DSITMS.

Direct Sampling Ion Trap Mass Spectrometry is a method for the quantitative measurement, continuous real-time monitoring, and quantitative and qualitative preliminary screening of VOCs in water, soil, and air (Wise et al, 1997). It is applicable to the determination of VOCs in batch samples taken to the laboratory and to on-site measurement and monitoring. It is best suited for the routine quantitative monitoring of sampling locations characterized once using standard gas chromatography mass spectrometry methods, for analyzing samples for the presence of VOCs, and for support of site characterization and remediation activities requiring the analysis of large numbers of samples in a short period of time or requiring on-line continuous monitoring. It is applicable to the qualitative and quantitative analysis of unknown (previously uncharacterized) samples provided that the absence of interferences can be documented. This procedure is not applicable if results are required for individual positional isomers (e.g., o,m,p-xylenes) or individual geometric isomers (e.g., cis/trans ethenes) unless unique operating conditions are developed and demonstrated which make it possible. Isomer distribution must be determined at least once using gas chromatography or gas chromatography mass spectrometry methods. 
Validation data has been collected comparing in situ MIP/DSITMS data to data for samples collected by US EPA sampling Method 5035 and analysis Method 8260 . The validation data set confirms that, given the limitations of DSITMS state above, the MIP/DSITMS method produces real-time data adequate for rapid site screening to assist in locating monitoring wells and conventional soil sampling.

\section{Quality Control}

1. Mass axis calibration of the DSITMS should be run daily using an acceptable calibration compound such as perflourotributylamine (PFTBA). Record the results of mass axis calibration for future reference.

2. A blank sample should be run for background subtraction, to ensure there is no carryover in the transfer line, any time samples are run having $>500 \mathrm{ppm}$ of VOC contamination, and between analysis of samples from different sources. At least one blank sample should be analyzed at the end of every penetration upon retraction.

3. A calibration curve should be developed using laboratory prepared standards of known concentrations bracketing the expected contaminant concentrations for a particular site.

4. Once calibration is achieved, analyze calibration check standards an minimum of once after each penetration is completed MIP/DSITMS. Corrective action is required when ever the calibration factor (slope of calibration curve) varies by $>2$ standard deviations from the mean value developed during calibration (see 3.) and subsequent analyses of calibration check standards. Corrective actions include, but are not limited to, system leak checking, evaluation of current calibration standard relative to the Performance Evaluation Check Standard (PECS; see 5. below) and complete recalibration.

5. Externally prepared PECS should be run daily at startup. Corrective action is required whenever the PECS results are significantly different form the true value (i.e. results do not fall within 2 standard deviations of the historic mean value developed for the analytical system).

6. Operating conditions used to generate the calibration curve should not be changed during sample analysis. Critical operating parameters that affect system sensitivity are carrier gas flow rate of the MIP, membrane temperature and DSITMS set points for electron multiplier voltage (EM), ionization time (IT) and filament current.

\section{Interferences}

False positives may occur for compounds yielding ions with the same mass to charge ratio $(\mathrm{m} / \mathrm{z})$ values as the characteristic ions of the targeted VOC . Also cis and trans isomers yielding the same $\mathrm{m} / \mathrm{z}$ can not always be distinguished. Whenever absolute identification of 
analytes with identical $\mathrm{m} / \mathrm{z}$ is required, confirmatory analysis should be obtained for a positive response (i.e. verification by US EPA SW 846 Methods).

\section{Materials}

Cone penetrometer truck with direct push well capability (ASTM, 1995).

Direct Sampling Ion Trap Mass Spectrometer (Finnigan Magnum/ITMS 40 or Varian Saturn; retrofitted with direct sampling inlet); (Wise et al, 1997).

Membrane Interface Probe and controller (Geoprobe Systems, Inc.)

Gas-Tight Syringes (10 to $100 \mu \mathrm{L})$

250 Volumetric flasks

$10 \mathrm{~mL}$ volumetric flasks

$4 \mathrm{~mL}$ screw cap vials with teflon lined caps

Flow Meter (digital type preferred)

Calibration jig for the MIP

\section{Reagents}

Helium, 99.9999\% purity

Methanol, purge and trap grade

Milli-Q or equivalent Water

Neat Volatile Materials, $99 \%$ purity for standards preparation or purchased premade standard solutions

Externally prepared performance evaluation check standard solutions

\section{Membrane Interface Probe}

1. Set flow rate of He to MIP module between $40-50 \mathrm{~mL} /$ minute at a regulated pressure not greater than 20 psi. 
2. Interface MIP carrier gas return line to inlet of heated DSITMS interface.

3. Heat MIP to $120^{\circ} \mathrm{C}$ and acquire 3 minute background data file using DSITMS.

4. Cool MIP to $<40^{\circ} \mathrm{C}$, place calibration jig around membrane, add sand and water. Acquire 3 minute background data file using DSITMS.

\section{Instrument Settings for Direct Sampling Ion Trap Mass Spectrometer}

1. Check DSITMS heater temperature, adjust if necessary per instrument manufactures instructions (normally between $150^{\circ}-200^{\circ} \mathrm{C}$ ).

2. Check critical DSITMS parameters: EM voltage, filament current and IT, adjust if necessary per instrument manufactures instructions .

3. Calibrate the DSITMS mass axis according to the manufactures' instruction. Print a hard copy of the mass axis calibration and archive.

4. Analyze a mid to low concentration calibration standard to access system sensitivity (see details of calibration standard analysis in Quantitative Calibration of MIP/DSITMS Sensor below). Adjust DSITMS operating parameters as needed to achieve desired sensitivity.

\section{Quantitative Calibration of MIP/DSITMS Sensor}

1. Prepare stock standard solutions for analytes of interest by weighing neat $(99 \%)$ VOC analytes into a $10 \mathrm{~mL}$ vol. flask containing approximately $7-8 \mathrm{~mL}$ methanol. Be careful to ensure that the neat analyte is dropped directly into the methanol and does not touch the unwetted glass surface of the vol. flask. Prepare stock solutions in the concentration ranges of 1-5 mg/mL. Multiple analyte mixtures in a single stock solution are acceptable as long as no analytes yielding identical $\mathrm{m} / \mathrm{z}$ are mixed (see Inferences). Details of VOC stock solution preparation can be found in US EPA Method 8260.

2. Prepare aqueous dilutions of the calibration standards in reagent water by filling a $250 \mathrm{~mL}$ vol. flask with water and injecting a measured volume of the methanol stock solution to obtain the desired aqueous concentration. A gas tight syringe should be used for this dilution (clean thoroughly with methanol after use). It is important to inject the methanol solution below the water surface in the vol. flask and to gently invert the flask three times to mix the aqueous standard dilution. Vigorous shaking of the standard dilution will cause low, erratic response during subsequent analysis.

3. Insure that the MIP heater is turned off and the membrane is $<40^{\circ} \mathrm{C}$. Place calibration jig on MIP with the membrane section in the middle of the jig. Using an aqueous standard prepared as 
described in 2., gently pour standard and sand at constant rates into the calibration jig. Simultaneously turn on the MIP heater and begin DSITMS data acquisition.

4. Analyze four different concentrations of dilutions in duplicate covering the desired concentration range. Make dilutions, one at a time as described in 2 . and analyze immediately. Do not batch the preparation of dilutions in water as VOCs defuse out of the water in a short period of time. Once a dilution has been prepared as describe in 15 , place the in situ sparge module directly into the vol. flask containing the standard dilution. Record three minutes of data after beginning MIP heating (see Figure 1).

5. Analyze calibration standards at various intervals, such as when problems operating instrument occur, or whenever sample concentrations vary widely and at least once after every penetration (see Quality Control and Critical Parameters and Troubleshooting) .

6. Analyze a PECS at least once each day of operation. Keep a continuing graphical or tabular record of daily calibration check standards and PECS for determination of system performance. Take corrective action whenever calibration standards or PECS results do not meet QC criteria (see Quality Control).

\section{Analytical Procedure for MIP/DSITMS}

1. Analyze blank water/sand sample before each penetration.

2. Prepare DSITMS data acquisition files for all planned sampling depths before penetration begins. Record data file names and sampling depths in the field sampling logbook.

3. Insure the MIP membrane is hot $\left(100-120^{\circ} \mathrm{C}\right)$. Push the MIP to the first sampling depth.

4. Begin data acquisition as soon as depth is achieved. Record minimum temperature of membrane during push to sampling depth (membrane cools during pushing).

5. Save DSITMS data file and prepare the next DSITMS acquisition file before advancing to the next sampling depth.

6. Repeat 2-5 for each sampling depth during penetration.

7. Analyze blank and at least on calibration check standard after retraction of MIP from penetration. Check system response of standard to insure continuing calibration (see Quality Control). 


\section{Calculate Results}

1. Determine relevant $\mathrm{m} / \mathrm{z}$ values to quantify specific analytes of interest (Table $\mathrm{A}$ ).

2. Plot selected ion profiles for $\mathrm{m} / \mathrm{z}$ of each analyte.

3. Integrate area for relevant $\mathrm{m} / \mathrm{z}$ values over a consistent number of scans (typically 80 to 100 scans). Actual sample integration intervals should always be the same number of scans as that used for calibration data quantification.

4. Use response factor determined from calibration curve for each analyte to calculate the concentration of analyte present in the sample.

5. Depending on the manufacturer of the ITMS, software for automation of calibration and sample data reduction may be available.

\section{Method Performance}

\section{Accuracy and Precision}

The MIP/DSITMS is currently under development and evaluation of field performance is underway. Current validation data indicates the system capable of rapid site screening providing data that can be used to place a minimum number of conventional monitoring wells or soil sampling borings. The PECS analysis data with commercial sand and VOC spiked water indicate accurate reponse at the single $\mathrm{mg} / \mathrm{kg}$ level. Precision during calibration indicates repeatable response within a factor of 2 with trained operators.

\section{Detection Limits}

Limit of detection (LOD) calculations are conducted using the U.S. EPA method proscribed in SW 846 (). This method involves $n$ replicate measurements of a low but detectable analyte concentration, estimation of analytical system noise as the variance of the $\mathrm{n}$ replicate measurements and calculation of LOD using the equation:

$$
\mathrm{LOD}=\mathrm{t}_{\mathrm{n}-1, \alpha / \mathrm{s}} \mathrm{S} \quad \text { (Equation 1) }
$$

where $t_{n-1, \alpha / s}$ is the student $t$ value for $n$ replicates at the $95 \%$ confidence level and $S$ estimate of the standard deviation. For $n$ values between 5 and 9 , the $t_{n-1, \alpha / s}$ ranges between 2.78 and 2.23. Measurements for LOD calculations are made using the entire MIP/DSITMS sensing system, therefore measuring the expected system performance in the direct push well. Typical LOD values calculated for data obtained in actual field operations are consistently in the $100 \mu \mathrm{g} / \mathrm{L}$ range. 


\section{Time Considerations}

Absolute time required for a single iteration of pushing to multiple sampling depths and making a number of MIP/DSITMS measurements is dependent on the total depth and sampling resolution desired. Each DSITMS analysis requires 3 minutes to complete. Estimates of time required for a single complete iteration range from one hour for penetrations $<25 \mathrm{ft}$ with up to ten discrete DSITMS measurements to approximately 3 hours for penetrations up to $150 \mathrm{ft}$ with up to 25 discrete DSITMS measurements.

\section{Verification Sampling for MIP/DSITMS}

The MIP/DSITMS system is intended to be used as a high level field screening technique to rapidly delineate the distribution of VOC contaminants in the subsurface. The data is intended to be used to accurately place a minimum number of conventional sampling points (soil bores and/or monitoring wells) for site characterization and monitoring. Therefore, a minimum of 5\% verification sampling and off site analysis by US EPA Method 8260 should be performed to confirm the results obtained at a particular site using the MIP/DSITMS (figure 2).

Select locations and depths for verification sampling to include a range of contaminant concentrations from non-detect to the maximum concentrations detected in situ by MIP/DSITMS. Obtain soil for verification samples by using direct push soil sampler advanced to depth using the CPT at locations offset no greater than 1 to $1.5 \mathrm{ft}$ horizontally from the MIP push location. Soil cores obtained for verification sampling should be subsampled using US EPA Method 5035 (i.e. subsamples placed immediately into tarred vials containing $5 \mathrm{~mL}$ methanol). Verification samples should be place on ice until shipped to the off site laboratory for analysis by US EPA Method 8260 . Note that clay subsamples that do not readily break up in the methanol when shaken should be manually broken into smaller pieces using a stainless steel spatula until the sample is completely submerged by the methanol. If soil remains above the surface of the methanol, the VOC contaminants will escape the extract and partition into the headspace of the vial causing erroneously low concentrations during analysis.

\section{Critical Parameters and Troubleshooting}

The MIP carrier gas flow rate and system response (i.e. slope of calibration curves) are linked. If the flow is change, re-calibration may be needed. The MIP operating temperature is critical to sensitivity and reproducibility. The membrane is impermeable to VOCs at temperatures less than $100^{\circ} \mathrm{C}$. Recommended operating temperature for the MIP is $120^{\circ} \mathrm{C}$.

The transfer line may become contaminated whenever highly contaminated soil and groundwater are analyzed ( $>500 \mathrm{ppm}$ ). If the analyte transfer line becomes contaminated with VOCs disconnect the analyte transfer line and the He supply line at the DSITMS inlet. Using a reducing union, back flush $1 / 8$ " analyte transfer line with 1/16" He supply line. Back flush for 
approximately 20 minutes, check the condition of the transfer line by reconnecting to the DSITMS inlet and analyzing a reagent water blank. Repeat Back flush as necessary.

Closely monitor the calibration check standards and PECS as these data a collected during the day. If a change is noted in the calibration check standard response, immediately analyze a PECS. If the PECS meets QC limits (see Quality Control), remake the standard stock solution as specified in Quantitative Calibration of MIP/DSITMS VOC Sensor. If the response of the PECS changes while the calibration check standard response meets QC limits, open an new vial of PECS and analyze. If the check standard and PECS both fail to meet QC limits, the problem is likely with the DSITMS or a leak in the in situ sparge module. Leak check in situ sparge module. If no leak is found and the response factors for both the check standard and PECS are low compared to QC limits, try adjusting the EM voltage upward to regain acceptable response. Periodic upward adjustment of the EM over its life is common. It should be noted that directly purging water into the DSITMS entrains significant water vapor and the life span of an EM in DSITMS is shorter than that of a conventional gas chromatograph/mass spectrometer system. 


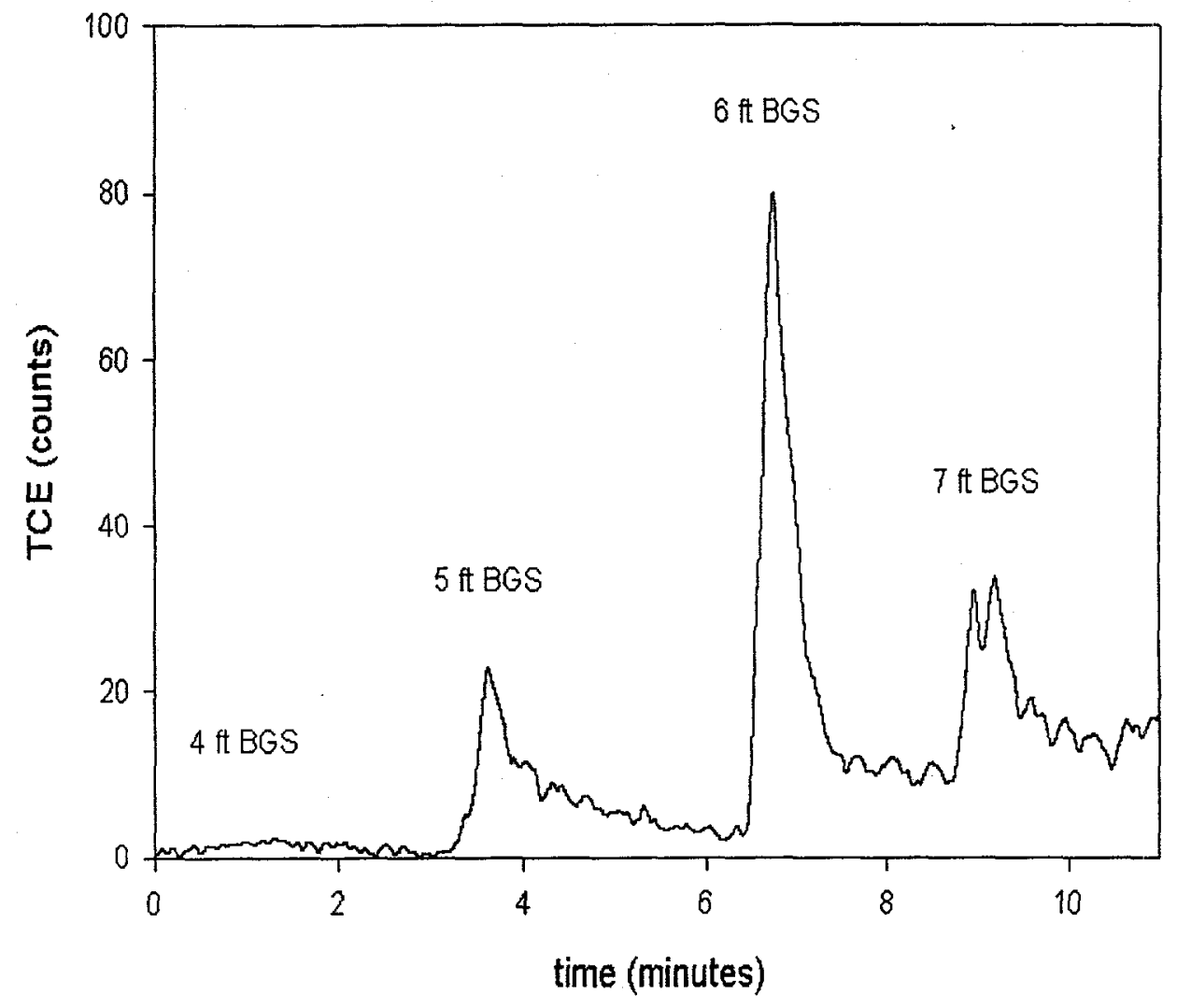

Figure 1. Selected ion profile for TCE (m/e 130) for typical measurements made using the MIP/DSITMS. Note different responses collected at four depths in less than eleven minutes. 


\section{Comparison of Analyses for VOCs in Soil}

Longhom Amy Ammunition Plant, Sept 1998

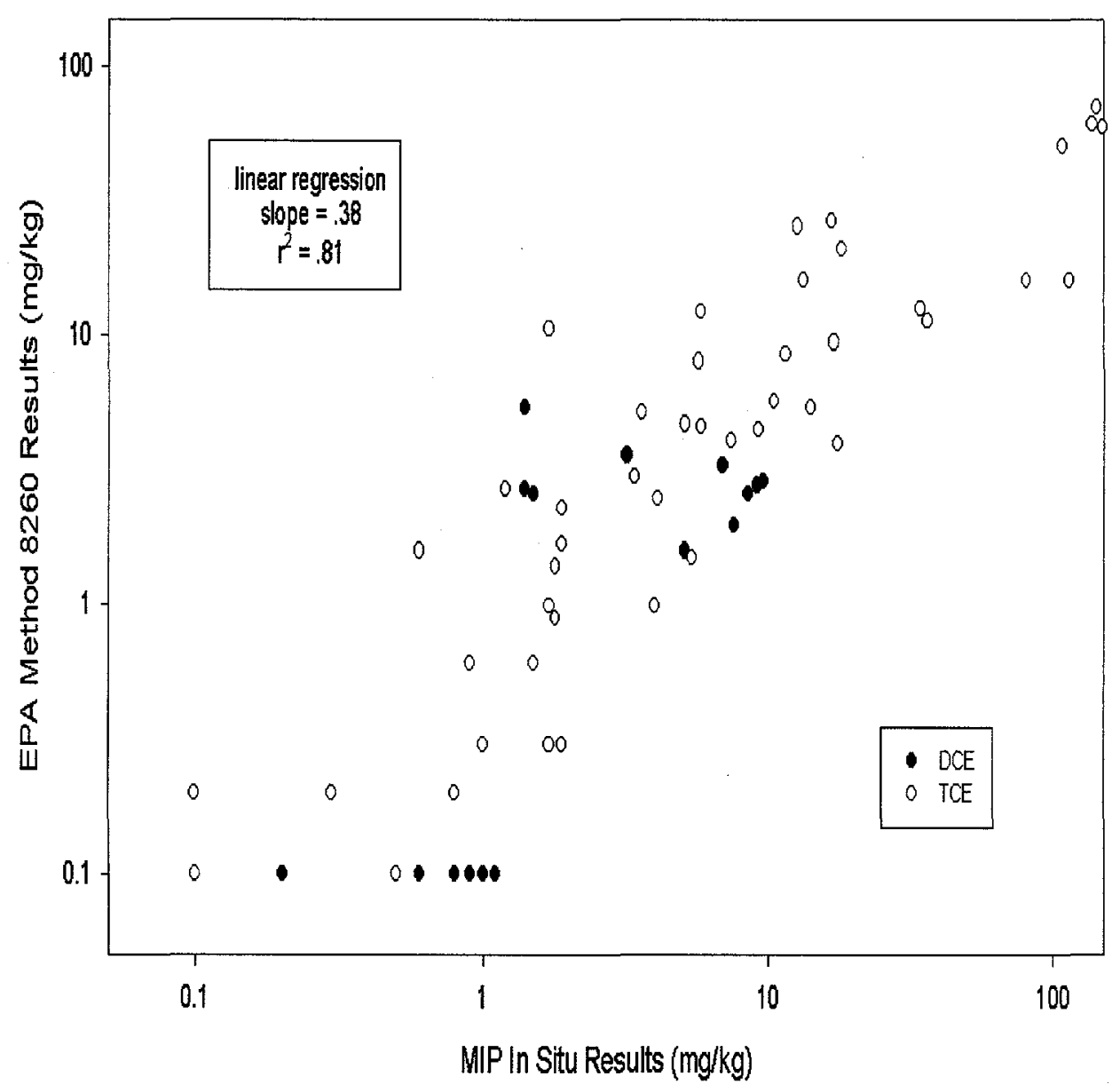

Figure 2. Comparison of MIP/DSITMS results with verification sample results of soil sampled by EPA Method 5035 and analyzed by EPA Method 8260 . 
Appendix B

\section{Longhorn Army Ammunition Plant MIP/DSITMS VOC Measurement Data}




\section{Appendix C}

\section{Lake City Army Ammunition Plant MIP/DSITMS VOC Measurement Data}




\section{Appendix B}

\section{Longhorn Army Ammunition Plant MIP/DSITMS VOC Measurement Data}




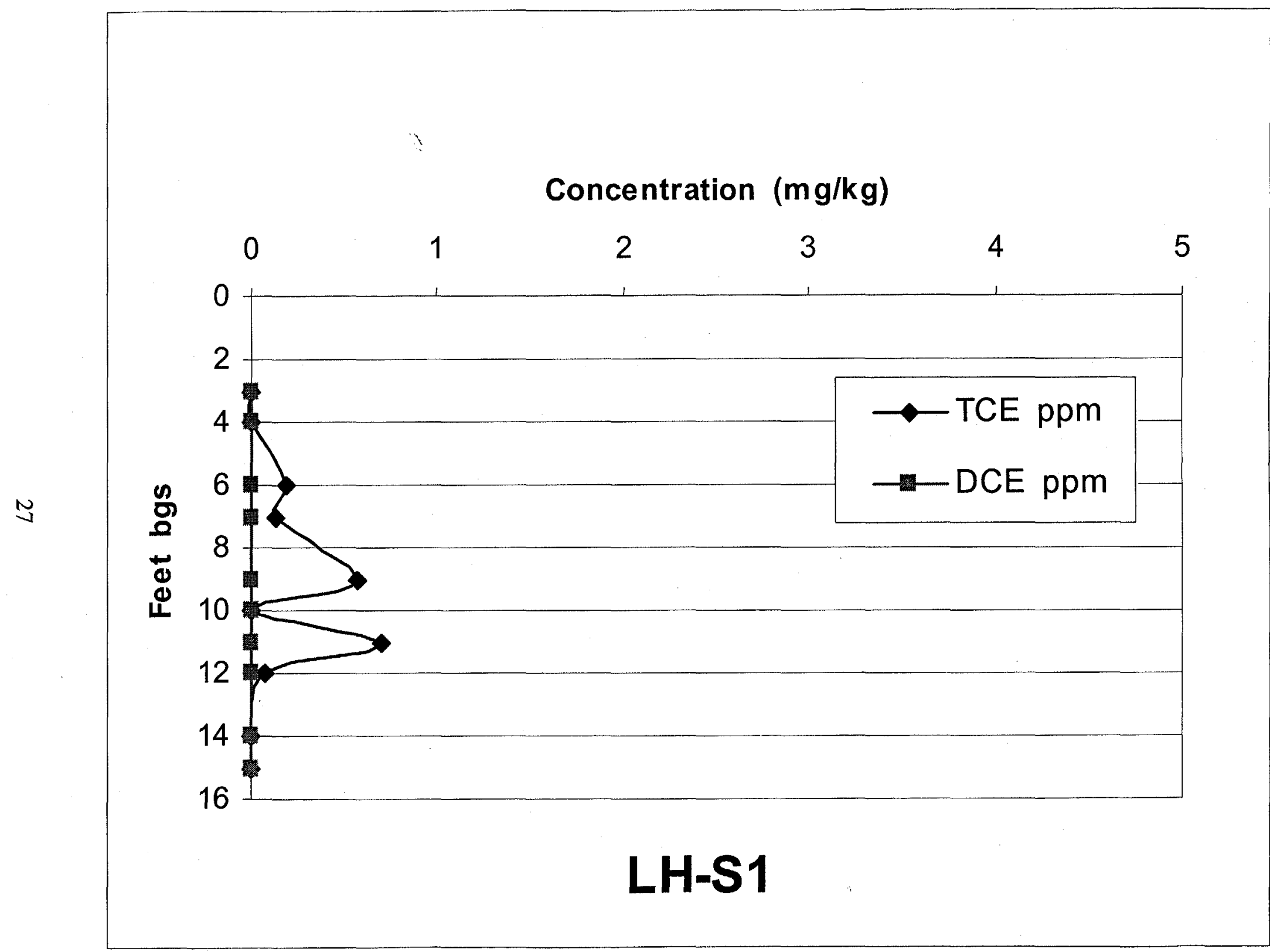

Figure B1. Results for MIP/DSITMS at location LH-S1 Longhorn Army Ammunition Plant. 


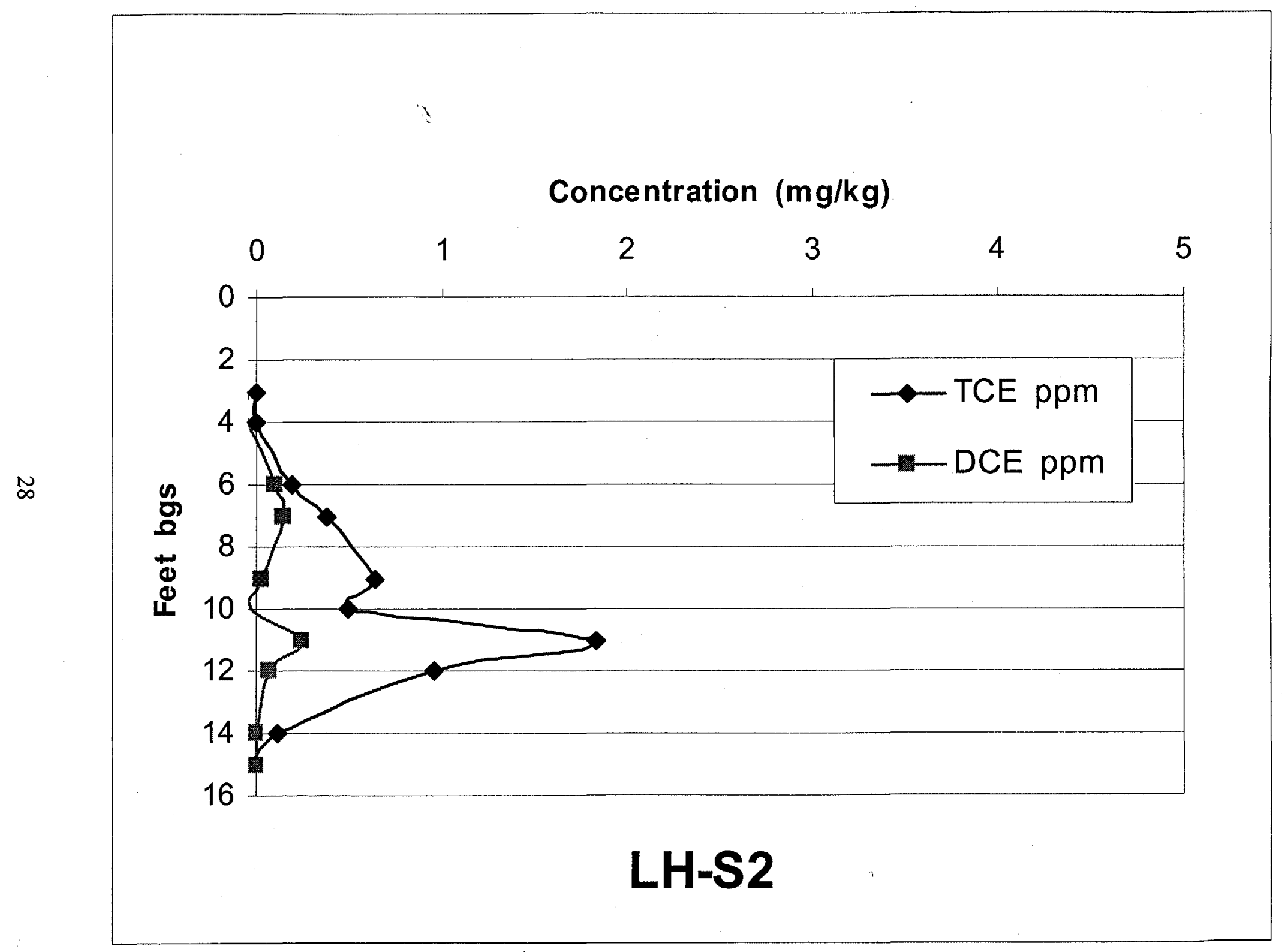

Figure B2. Results for MIP/DSITMS at location LH-S2 Longhorn Army Ammunition Plant. 


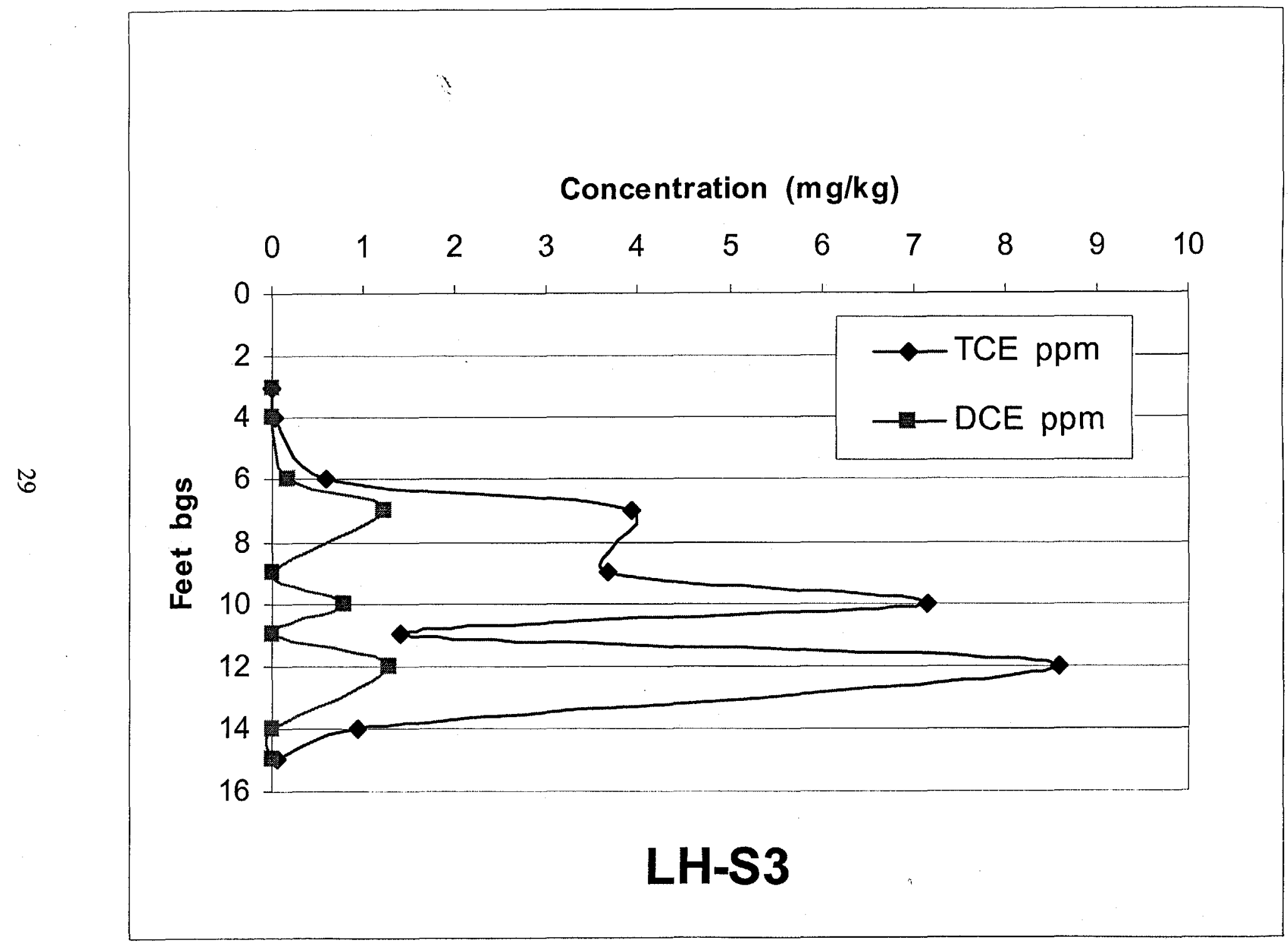

Figure B3. Results for MIP/DSITMS at location LH-S3 Longhorn Army Ammunition Plant. 


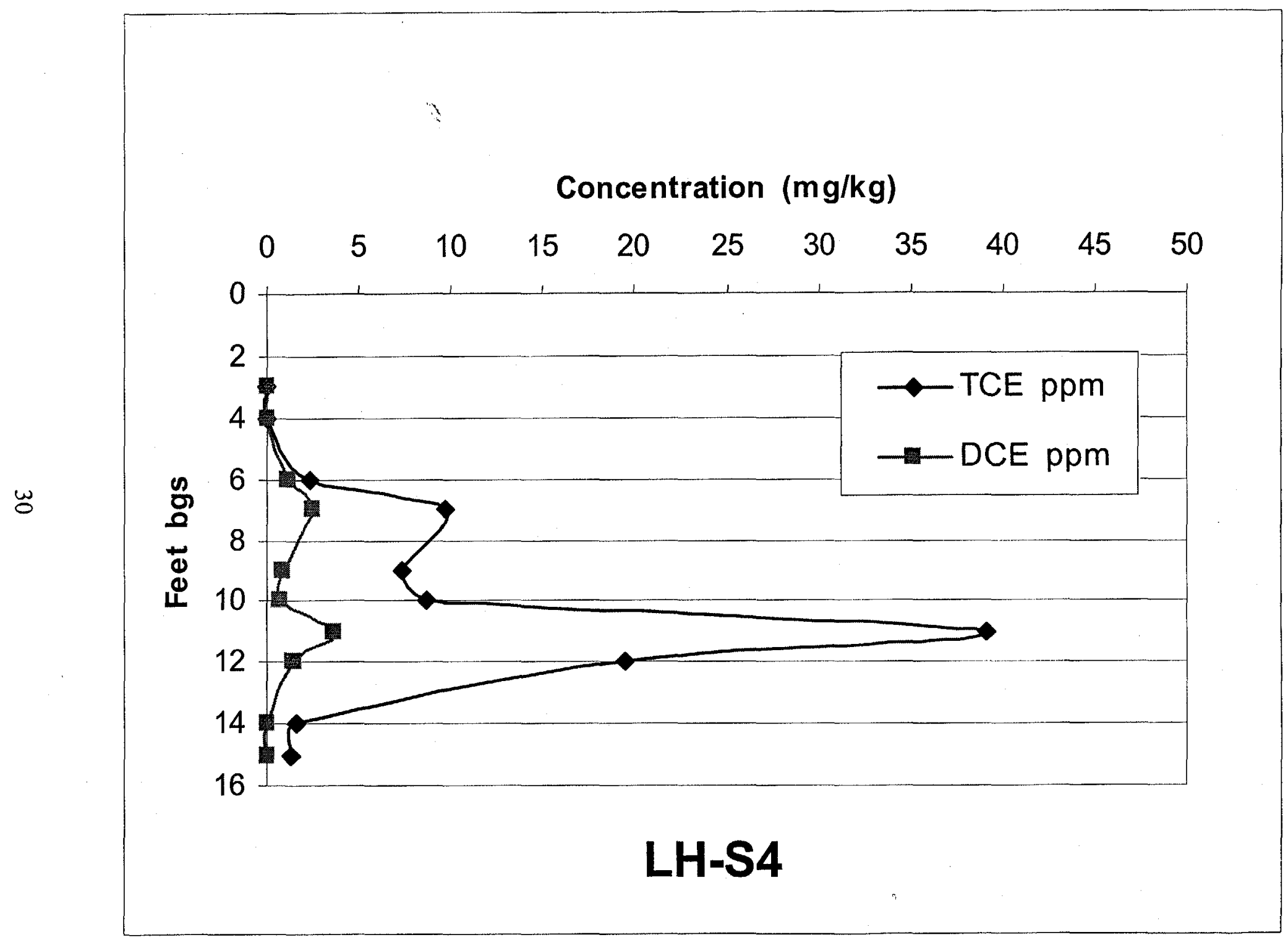

Figure B4. Results for MIP/DSITMS at location LH-S4 Longhorn Army Ammunition Plant. 


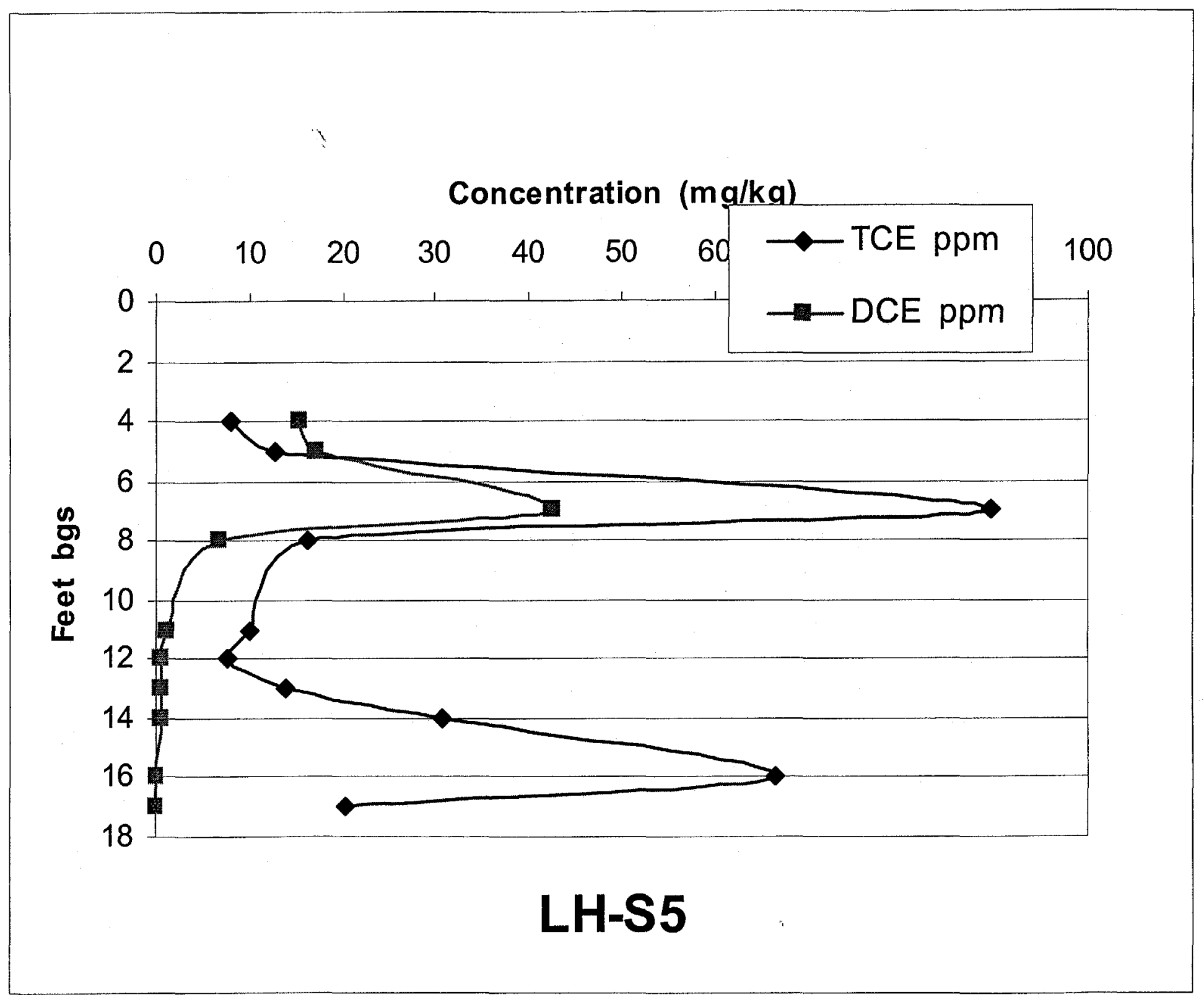

Figure B5. Results for MIP/DSITMS at location LH-S5 Longhorn Army Ammunition Plant. 
MIP In Situ Results at LHOLEO6

Longhorn Army Ammunition Plant, Sept 1998

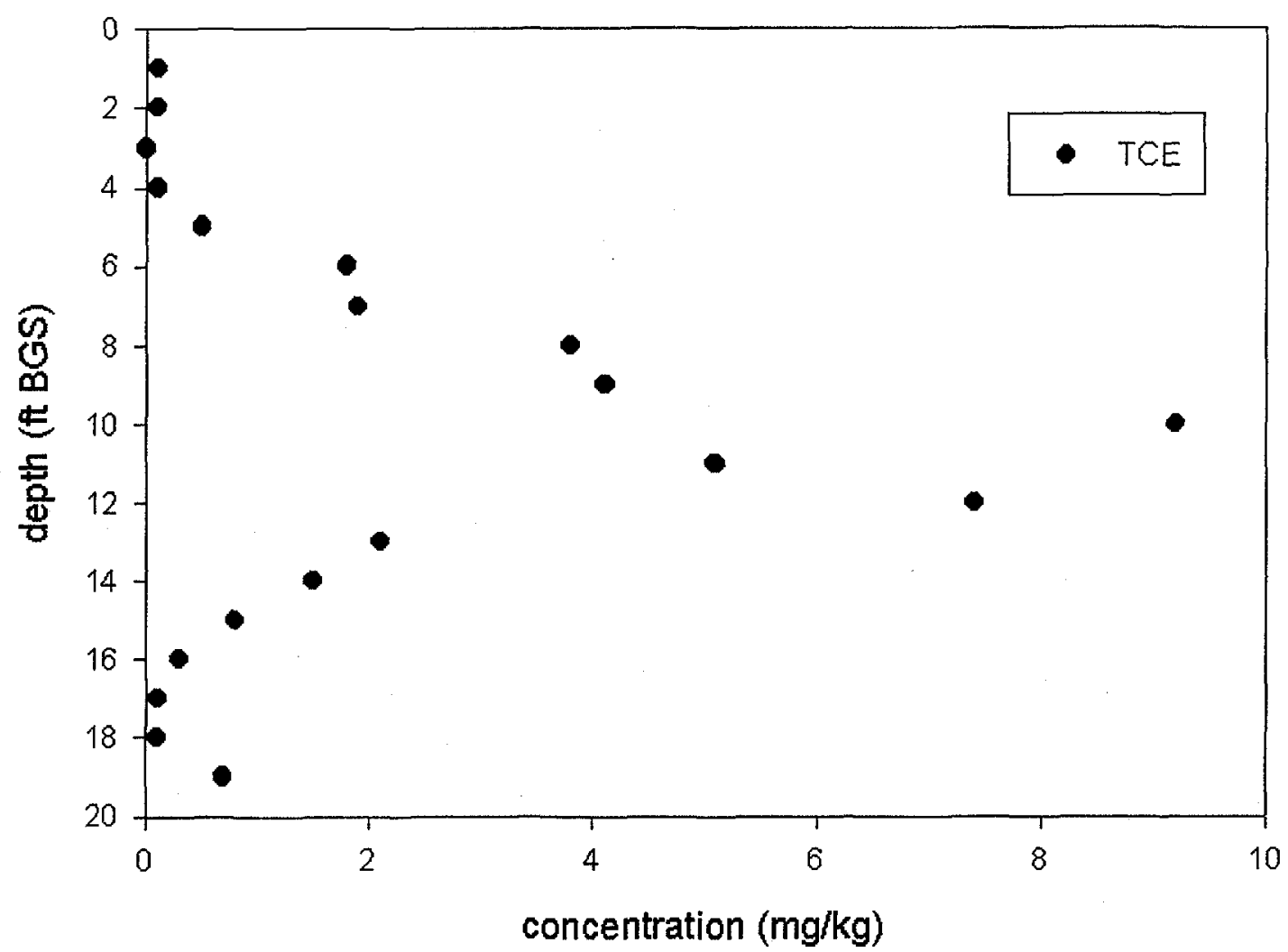

Figure B6. Results for MIP/DSITMS at location LH-S6 Longhorn Army Ammunition Plant. 
MIP In Situ Results at LHOLE08

Longhorn Army Ammunition Plant, Sept 1998

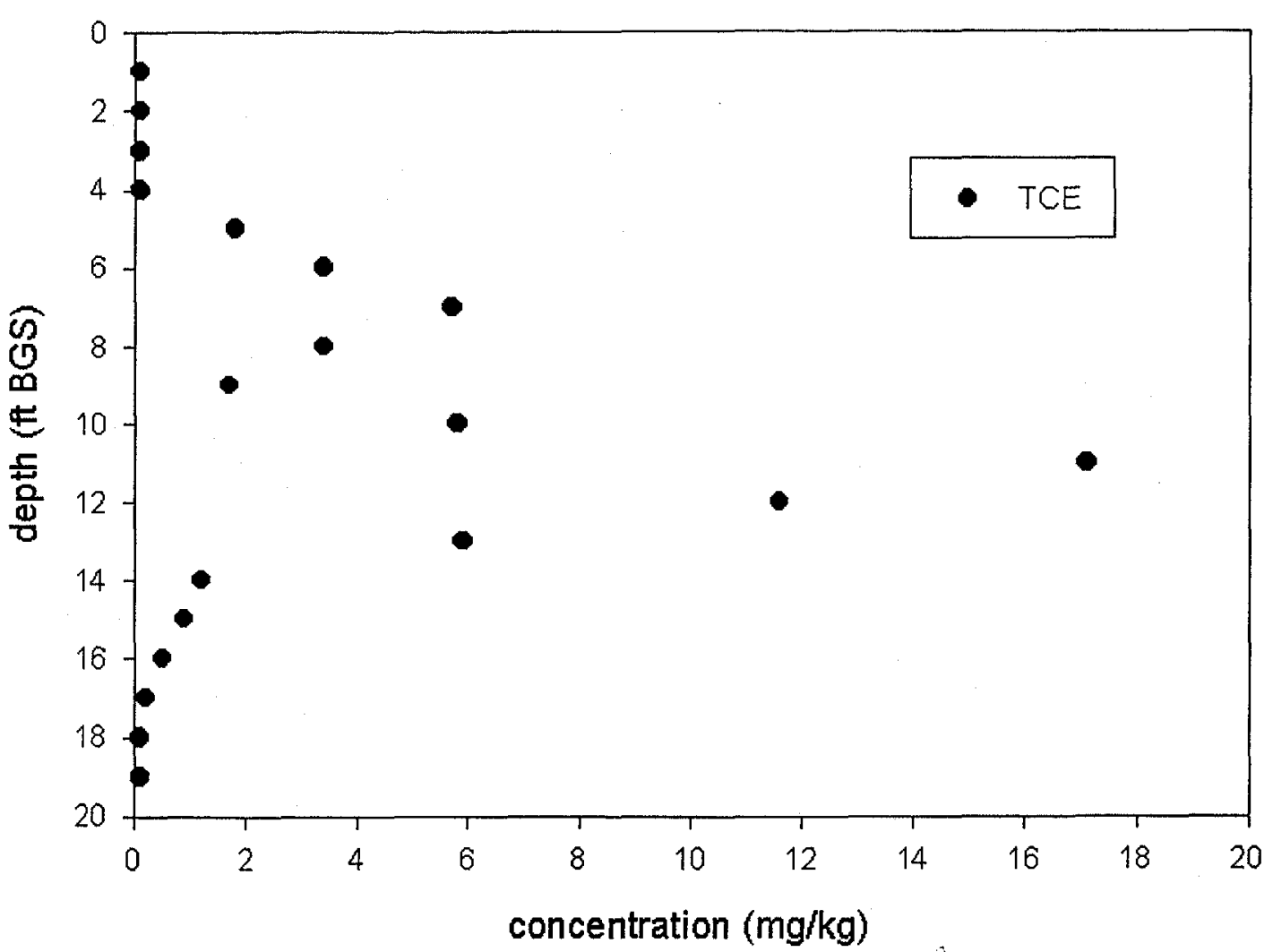

Figure B7. Results for MIP/DSITMS at location LH-S8 Longhorn Army Ammunition Plant. 
MIP In Situ Results at LHOLE09

Longhorn Army Ammunition Plant, Sept 1998

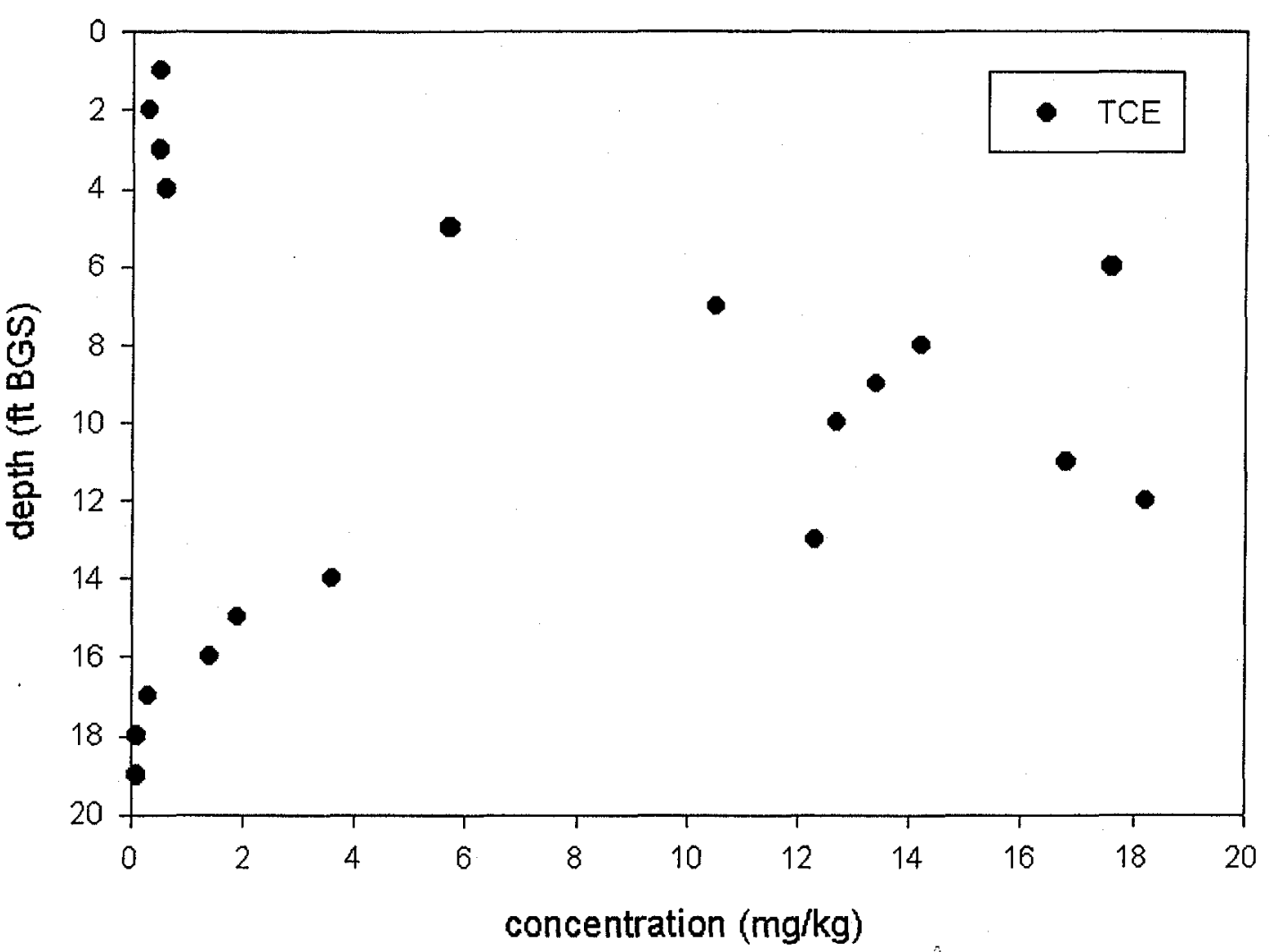

Figure B8. Results for MIP/DSITMS at location LH-S9 Longhorn Army Ammunition Plant. 
MIP In Situ Results at LHOLE15

Longhorn Army Ammunition Plant, Sept 1998

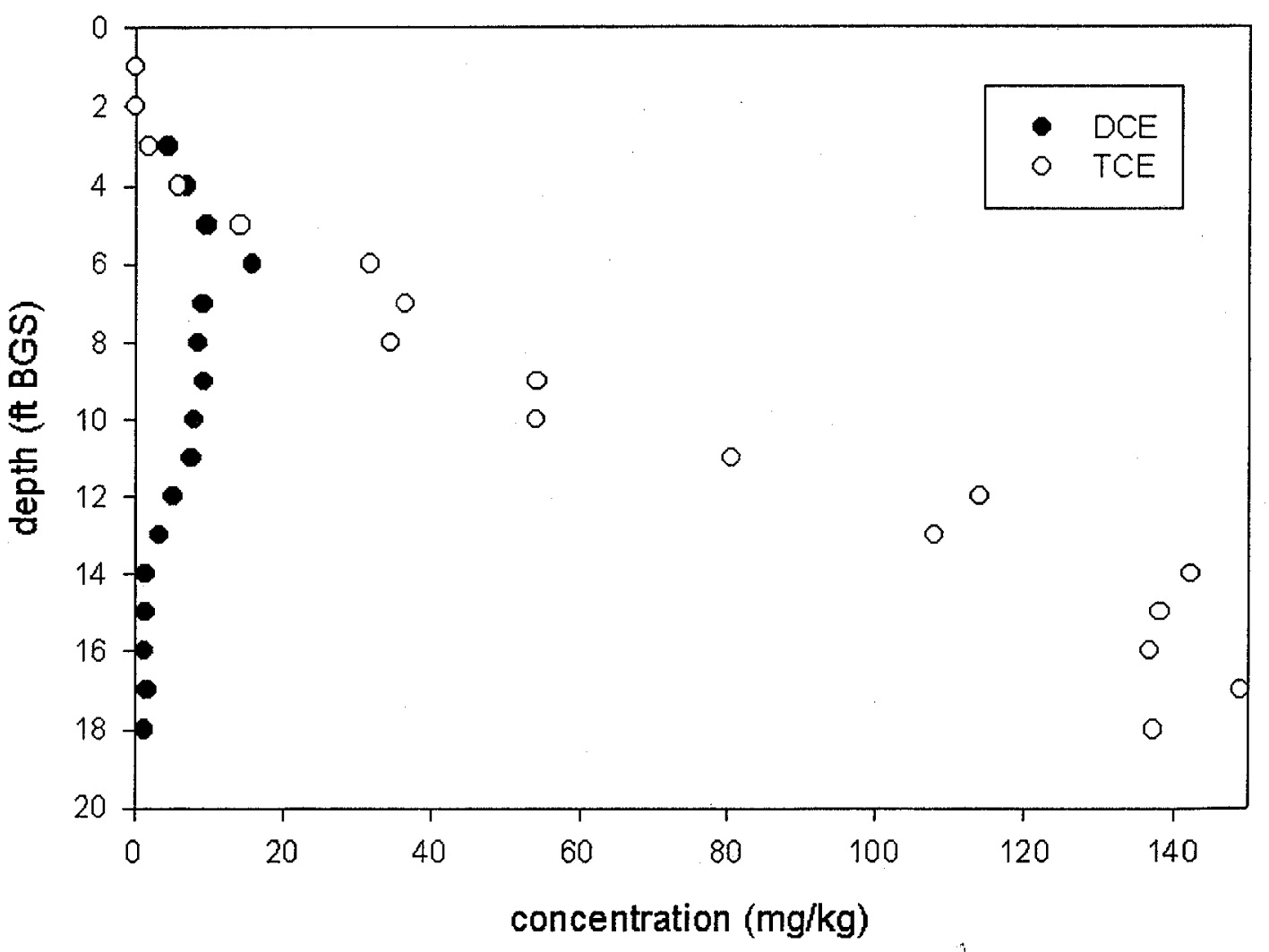

Figure B9. Results for MIP/DSITMS at location LH-S15 Longhorn Army Ammunition Plant. 


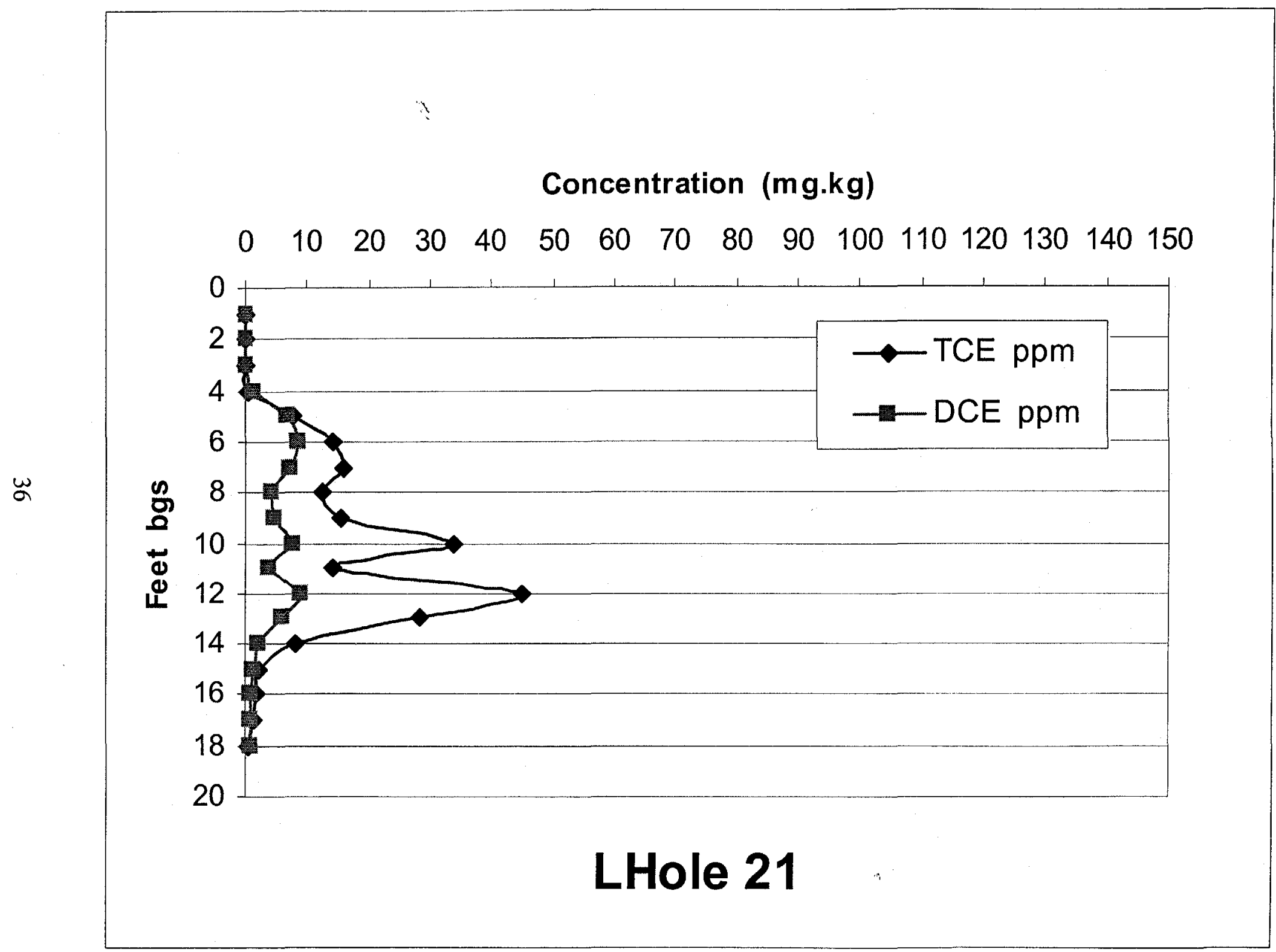

Figure B10. Results for MIP/DSITMS at location LH-21 Longhorn Army Ammunition Plant. 


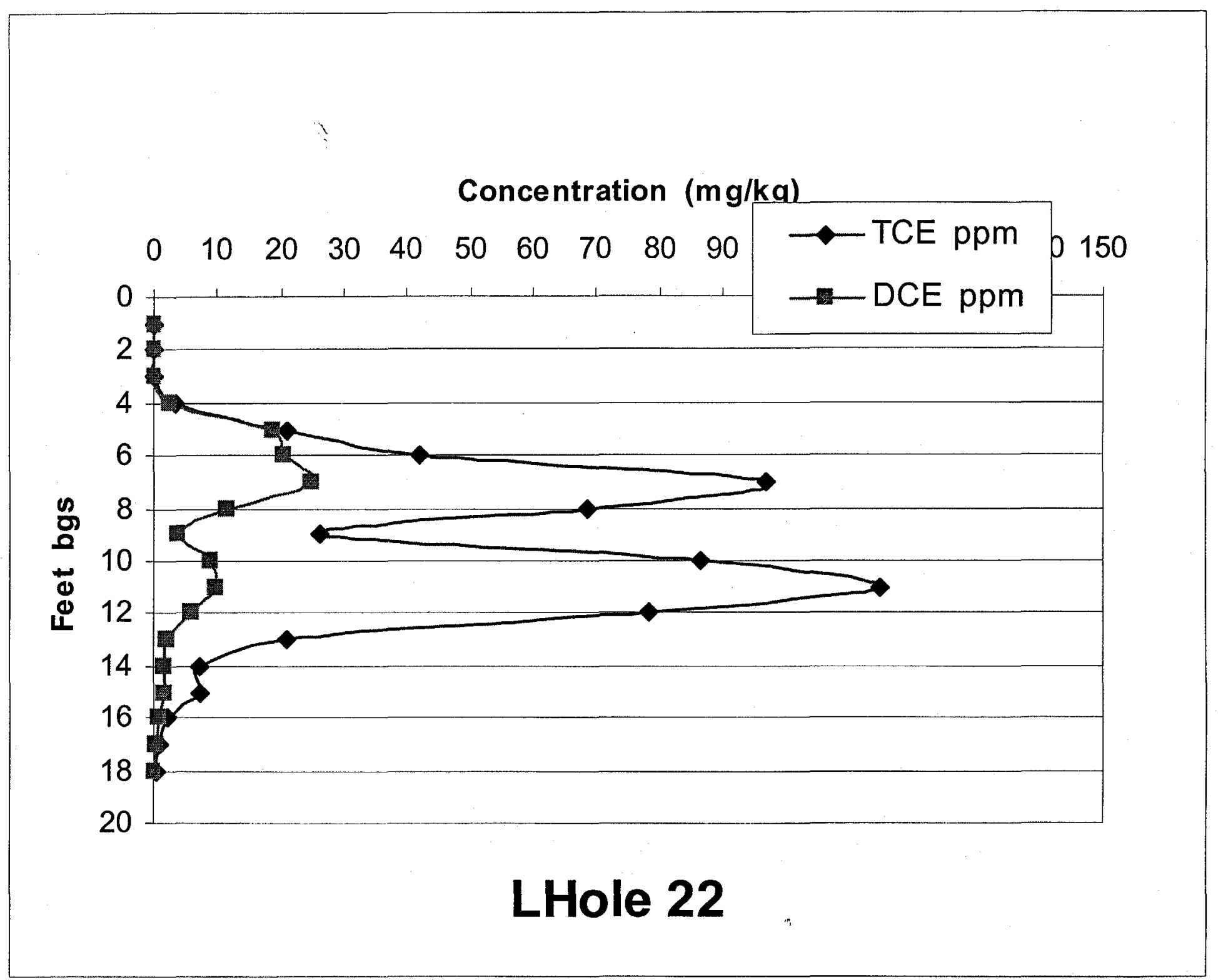

Figure B11 Results for MIP/DSITMS at location LH-22 Longhorn Army Ammunition Plant. 


\section{Appendix C}

\section{Lake City Army Ammunition Plant MIP/DSITMS VOC Measurement Data}


MIP/DSITMS Analysis

Lake City Army Ammunition Plant

all data reported as $\mathrm{ug} / \mathrm{L}=\mathrm{ppb}$

\begin{tabular}{|c|c|c|c|c|c|c|c|}
\hline & TCE & PCE & DCE & $\mathrm{CHCl} 3$ & Naphthalene & Aromatic * & VC \\
\hline $17 \mathrm{MP} 110-2$ & $\mathrm{ND}$ & ND & ND & $\mathrm{ND}$ & ND & ND & ND \\
\hline 17MP110-6 & ND & ND & ND & ND & ND & ND & ND \\
\hline 17MP110-8 & ND & ND & ND & ND & ND & ND & ND \\
\hline 17MP110-12 & ND & ND & ND & ND & ND & 4,000 & ND \\
\hline 17MP110-14 & ND & ND & $\mathrm{ND}$ & ND & ND & 8,300 & ND \\
\hline 17MP110-16 & ND & ND & ND & ND & ND & 2,200 & ND \\
\hline $17 \mathrm{MP} 110-18$ & ND & ND & ND & ND & ND & 1,000 & ND \\
\hline $17 \mathrm{MP} 110-20$ & 1,900 & 350 & 1,800 & ND & ND & ND & ND \\
\hline $17 \mathrm{MP} 110-22$ & 3,400 & 1,000 & 2,400 & ND & ND & ND & ND \\
\hline $17 \mathrm{MP} 110-24$ & 6,800 & 1,700 & 4,000 & ND & ND & ND & ND \\
\hline $17 M P 110-26$ & 12,000 & 2,200 & 4,900 & ND & ND & ND & ND \\
\hline $17 \mathrm{MP} 110-28$ & 21,000 & 2,300 & 4,200 & $\mathrm{ND}$ & ND & ND & ND \\
\hline $17 \mathrm{MP} 110-30$ & 11,000 & 1,500 & 1,500 & $\mathrm{ND}$ & ND & ND & ND \\
\hline $17 \mathrm{MP} 110-32$ & 6,000 & 1,100 & 740 & ND & ND & ND & ND \\
\hline $17 \mathrm{MP} 110-34$ & 2,600 & 310 & ND & ND & ND & ND & ND \\
\hline $17 \mathrm{MP} 110-36$ & 1,700 & $\mathrm{ND}$ & ND & ND & ND & ND & ND \\
\hline $17 \mathrm{MP} 110-38$ & 6,100 & 660 & ND & ND & ND & ND & ND \\
\hline $17 \mathrm{MP} 110-40$ & 73,000 & 2,800 & 4,200 & ND & ND & ND & ND \\
\hline $17 \mathrm{MP110-42}$ & 320,000 & 23,000 & 24,000 & ND & ND & $\mathrm{ND}$ & ND \\
\hline 17MP111-2 & ND & ND & $\mathrm{ND}$ & ND & ND & ND & $\mathrm{ND}$ \\
\hline 17MP111-4 & ND & ND & ND & ND & ND & ND & ND \\
\hline $17 \mathrm{MP} 111-6$ & ND & ND & ND & ND & ND & ND & ND \\
\hline $17 \mathrm{MP} 111-8$ & ND & ND & ND & ND & ND & ND & ND \\
\hline 17MP111-10 & ND & ND & ND & ND & ND & ND & ND \\
\hline 17MP111-12 & ND & ND & ND & ND & ND & ND & ND \\
\hline $17 \mathrm{MP} 111-14$ & ND & ND & $\mathrm{ND}$ & ND & ND & ND & ND \\
\hline 17MP111-16 & ND & ND & $\mathrm{ND}$ & ND & 330 & ND & ND \\
\hline $17 \mathrm{MP} 111-18$ & ND & ND & ND & ND & 390 & ND & ND \\
\hline 17MP111-20 & ND & $\mathrm{ND}$ & ND & ND & 400 & ND & ND \\
\hline $17 \mathrm{MP} 111-22$ & $\mathrm{ND}$ & ND & ND & ND & 390 & ND & ND \\
\hline 17MP111-24 & ND & $\mathrm{ND}$ & ND & ND & 370 & ND & ND \\
\hline $17 \mathrm{MP} 111-26$ & ND & ND & ND & ND & 350 & ND & ND \\
\hline 17MP111-28 & $\mathrm{ND}$ & ND & ND & ND & 330 & ND & ND \\
\hline $17 \mathrm{MP} 111-30$ & ND & ND & ND & $\mathrm{ND}$ & 320 & ND & ND \\
\hline $17 \mathrm{MP} 111-32$ & ND & ND & ND & ND & 300 & ND & ND \\
\hline 17MP111-34 & $\mathrm{ND}$ & ND & ND & ND & 220 & ND & ND \\
\hline $17 \mathrm{MP} 111-36$ & ND & ND & ND & ND & 90 & ND & ND \\
\hline 17MP111-38 & $\mathrm{ND}$ & ND & ND & ND & ND & ND & ND \\
\hline$\triangle 7 \mathrm{MP} 111-40$ & $\mathrm{ND}$ & ND & ND & ND & ND & ND & $\mathrm{ND}$ \\
\hline $17 \mathrm{MP} 111-42$ & $\mathrm{ND}$ & ND & ND & ND & ND & ND & ND \\
\hline $17 \mathrm{MP} 111-44$ & ND & ND & ND & ND & ND & ND & ND \\
\hline
\end{tabular}

* toluene, ethylbenzene, and/or xylene

page 1 
MIP/DSITMS Analysis

Lake City Army Ammunition Plant

all data reported as $u g / L=p p b$

\begin{tabular}{|c|c|c|c|c|c|c|c|}
\hline & TCE & $\mathrm{PCE}$ & DCE & $\mathrm{CHCl} 3$ & $\mathrm{CCl} 4$ & Aromatic * & VC \\
\hline 17MP112-12 & 98,000 & 44,000 & 650,000 & ND & ND & 680,000 & 840,000 \\
\hline 17MP112-14 & 13,000 & 6,900 & 510,000 & ND & $\mathrm{ND}$ & 540,000 & 680,000 \\
\hline $17 \mathrm{MP} 112-16$ & 5,000 & 2,200 & 240,000 & ND & ND & 250,000 & 340,000 \\
\hline 17MP112-18 & 2,500 & 1,300 & 110,000 & ND & ND & 98,000 & 150,000 \\
\hline $17 \mathrm{MP} 112-20$ & 1,600 & 890 & 40,000 & ND & ND & 32,000 & 50,000 \\
\hline 17MP112-22 & 1,800 & 740 & 22,000 & ND & ND & 18,000 & 27,000 \\
\hline 17MP112-24 & 3,000 & 700 & 12,000 & ND & ND & 12,000 & 14,000 \\
\hline $17 \mathrm{MP} 112-26$ & 3,300 & 670 & 8,100 & ND & ND & 9,000 & 9,800 \\
\hline 17MP112-28 & 1,600 & 590 & 6,000 & ND & ND & 6,500 & 7,200 \\
\hline 17MP112-30 & 830 & 530 & 4,700 & ND & ND & 4,900 & 5,600 \\
\hline $17 \mathrm{MP} 112-32$ & 710 & 490 & 3,800 & ND & ND & 3,500 & 4,400 \\
\hline 17MP $112-34$ & 640 & 460 & 3,300 & ND & ND & 2,500 & 3,600 \\
\hline $17 \mathrm{MP} 112-36$ & 720 & 450 & 2,600 & ND & ND & 2,000 & 3,000 \\
\hline 17MP112-38 & 14,000 & 600 & 3,300 & ND & ND & 1,700 & 3,200 \\
\hline 17MP112-40 & 140,000 & 2,500 & 10,000 & ND & ND & 9,900 & 9,800 \\
\hline 17MP112-42 & 460,000 & 11,000 & 27,000 & ND & ND & 91,000 & 37,000 \\
\hline 17MP112-44 & $1,700,000$ & 57,000 & ND & ND & ND & 440,000 & ND \\
\hline 17MP112-45 & $1,800,000$ & 110,000 & ND & $\mathrm{ND}$ & ND & 530,000 & ND \\
\hline $17 \mathrm{MP113-3.1}$ & ND & ND & ND & ND & ND & ND & ND \\
\hline $17 \mathrm{MP} 113-6.4$ & ND & ND & ND & ND & ND & ND & ND \\
\hline 17MP113-9.7 & $\mathrm{ND}$ & ND & ND & $\mathrm{ND}$ & ND & ND & ND \\
\hline 17MP113-12.9 & $\mathrm{ND}$ & ND & $\mathrm{ND}$ & ND & ND & ND & ND \\
\hline $17 \mathrm{MP} 113-16.2$ & ND & ND & 3,200 & ND & ND & ND & 3,200 \\
\hline 17 MP113-19.5 & ND & ND & 34,000 & ND & ND & ND & 37,000 \\
\hline 17MP113-22.8 & ND & ND & 120,000 & ND & ND & ND & 140,000 \\
\hline 17MP113-26.0 & ND & $\mathrm{ND}$ & 530,000 & ND & ND & 150,000 & 640,000 \\
\hline $17 \mathrm{MP} 113-29.3$ & $2,600,000$ & 94,000 & 390,000 & ND & $\mathrm{ND}$ & 750,000 & 580,000 \\
\hline $17 \mathrm{MP} 113-32.7$ & $4,200,000$ & 230,000 & 280,000 & ND & ND & $1,000,000$ & ND \\
\hline $17 \mathrm{MP} 113-35.9$ & $4,100,000$ & 180,000 & ND & ND & $\mathrm{ND}$ & 930,000 & ND \\
\hline $17 \mathrm{MP} 113-39.1$ & $8,300,000$ & 340,000 & ND & $\mathrm{ND}$ & ND & $2,200,000$ & ND \\
\hline $17 \mathrm{MP} 113-40.0$ & $6,900,000$ & 340,000 & ND & ND & ND & $1,800,000$ & ND \\
\hline 17MP114-2 & ND & ND & ND & ND & ND & ND & ND \\
\hline 17MP114-4 & ND & ND & ND & ND & ND & ND & ND \\
\hline 17MP114-6 & ND & ND & ND & ND & ND & ND & ND \\
\hline 17MP114-8 & ND & ND & ND & ND & ND & $\mathrm{ND}$ & ND \\
\hline 17MP114-10 & ND & ND & ND & ND & ND & ND & $\mathrm{ND}$ \\
\hline 17MP114-12 & ND & ND & ND & $\mathrm{ND}$ & ND & ND & ND \\
\hline 17MP114-14 & $\mathrm{ND}$ & ND & ND & $\mathrm{ND}$ & ND & ND & ND \\
\hline $17 \mathrm{MP} 114-16$ & 750 & ND & ND & ND & ND & ND & ND \\
\hline 17MP114-18 & 1,100 & ND & 530 & ND & ND & ND & ND \\
\hline 17MP114-20 & 810 & ND & $\mathrm{ND}$ & ND & ND & ND & ND \\
\hline $17 \mathrm{MP} 114-22$ & 400 & ND & ND & ND & ND & ND & ND \\
\hline 17MP114-23.1 & 390 & ND & ND & ND & $\mathrm{ND}$ & ND & ND \\
\hline
\end{tabular}

* toluene, ethylbenzene, and/or xylene 
all data reported as $u g / L=p p b$

\begin{tabular}{|c|c|c|c|c|c|c|c|}
\hline & TCE & PCE & $\overline{D C E}$ & $\mathrm{CHCl} 3$ & $\mathrm{CCl} 4$ & Aromatic * & VC \\
\hline 17MP115-4 & $\mathrm{ND}$ & ND & ND & ND & ND & ND & ND \\
\hline 17MP115-6 & ND & ND & ND & ND & ND & $\mathrm{ND}$ & ND \\
\hline 17MP115-8 & ND & ND & ND & ND & ND & ND & ND \\
\hline 17MP115-10 & ND & ND & ND & ND & ND & ND & ND \\
\hline 17MP115-12 & ND & ND & ND & ND & ND & ND & ND \\
\hline 17MP115-14 & ND & ND & ND & ND & ND & ND & ND \\
\hline 17MP115-16 & 600 & ND & ND & ND & ND & ND & ND \\
\hline 17MP115-18 & ND & ND & ND & ND & ND & ND & ND \\
\hline 17MP115-20 & ND & ND & ND & ND & ND & ND & ND \\
\hline 17MP115-22 & ND & ND & ND & ND & ND & ND & ND \\
\hline 17MP115-24 & ND & ND & ND & ND & ND & ND & ND \\
\hline $17 M P 115-26$ & ND & ND & $\mathrm{ND}$ & ND & ND & ND & ND \\
\hline $17 \mathrm{MP} 115-27.3$ & ND & ND & ND & ND & ND & ND & ND \\
\hline $17 \mathrm{MP} 116-2$ & ND & ND & ND & ND & ND & ND & ND \\
\hline 17MP116-4 & ND & ND & ND & ND & ND & ND & ND \\
\hline 17MP116-6 & ND & ND & ND & ND & ND & ND & ND \\
\hline $17 \mathrm{MP} 116-8$ & ND & ND & ND & ND & ND & ND & ND \\
\hline $17 M P 116-10$ & $\mathrm{ND}$ & $\mathrm{ND}$ & 750 & ND & ND & ND & ND \\
\hline 17MP116-12 & 1,000 & 400 & 900 & ND & ND & ND & ND \\
\hline 17MP116-14 & 1,700 & 650 & 1,200 & ND & ND & ND & ND \\
\hline $17 \mathrm{MP} 116-16$ & 1,900 & 880 & 980 & ND & ND & ND & ND \\
\hline $17 \mathrm{MP} 116-18$ & 1,400 & 460 & 680 & ND & ND & ND & ND \\
\hline $17 \mathrm{MP} 116-20$ & 770 & ND & ND & ND & ND & ND & ND \\
\hline 17MP116-22 & ND & ND & ND & ND & ND & ND & ND \\
\hline 17MP116-24 & ND & ND & ND & $\mathrm{ND}$ & ND & ND & ND \\
\hline 17MP116-26 & ND & ND & ND & ND & ND & ND & ND \\
\hline 17MP117-1 & ND & ND & ND & ND & ND & ND & ND \\
\hline 17MP117-2 & ND & $\mathrm{ND}$ & ND & ND & ND & ND & ND \\
\hline $17 \mathrm{MP} 117-3$ & ND & ND & ND & ND & ND & ND & ND \\
\hline $17 \mathrm{MP} 117-4$ & ND & ND & $\mathrm{ND}$ & $\mathrm{ND}$ & ND & ND & ND \\
\hline $17 \mathrm{MP} 117-5$ & ND & ND & ND & ND & ND & ND & ND \\
\hline 17MP117-6 & ND & ND & ND & ND & ND & ND & ND \\
\hline 17MP117-7 & ND & ND & ND & ND & ND & ND & ND \\
\hline 17MP117-8 & ND & ND & ND & ND & ND & ND & ND \\
\hline 17MP117-9 & ND & ND & ND & ND & ND & ND & ND \\
\hline 17MP117-10 & ND & ND & ND & ND & ND & ND & ND \\
\hline 17MP117-11 & ND & ND & ND & ND & ND & ND & ND \\
\hline 17MP117-12 & ND & ND & ND & ND & ND & ND & ND \\
\hline $17 \mathrm{MP} 117-13$ & ND & ND & ND & ND & ND & ND & $\overline{N D}$ \\
\hline 17MP117-14 & ND & ND & ND & ND & ND & ND & ND \\
\hline 17MP117-15 & ND & ND & ND & ND & ND & ND & ND \\
\hline $17 \mathrm{MP} 117-16$ & ND & $\mathrm{ND}$ & ND & ND & ND & $\mathrm{ND}$ & ND \\
\hline
\end{tabular}


all cata reponod es wh $=p$

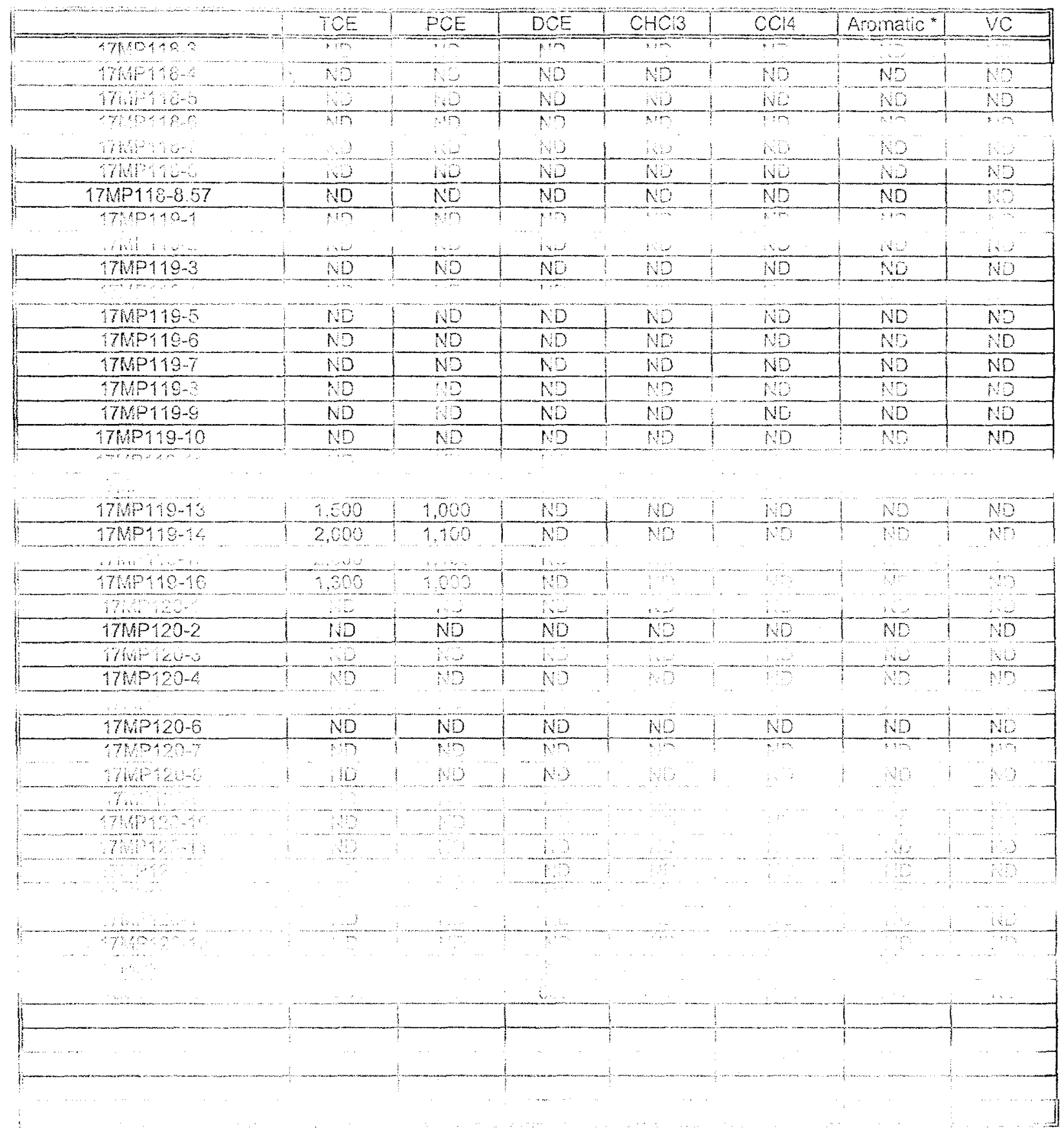

